\title{
Structure and variability of the Denmark Strait Overflow: Model and observations
}

\author{
R. H. Käse \\ Institut für Meereskunde an der Universität Kiel, Kiel, Germany
}

J. B. Girton

Woods Hole Oceanographic Institution, Woods Hole, Massachusetts, USA

T. B. Sanford

Applied Physics Laboratory and School of Oceanography, University of Washington, Seattle, Washington, USA

Received 18 July 2002; revised 4 November 2002; accepted 20 February 2003; published 7 June 2003.

[1] We report on a combined modeling and observational effort to understand the Denmark Strait Overflow (DSO). Four cruises over the course of 3 years mapped hydrographic properties and velocity fields with high spatial resolution. The observations reveal the mean path of the dense water, as well as the presence of strong barotropic flows, energetic variability, and strong bottom friction and entrainment. A regional sigma coordinate numerical model of interbasin exchange using realistic bottom topography and an overflow forced only by an upstream reservoir of dense fluid is compared with the observations and used to further investigate these processes. The model successfully reproduces the volume transport of dense water at the sill, as well as the 1000-m descent of the dense water in the first $200 \mathrm{~km}$ from the sill and the intense eddies generated at $1-3$ day intervals. Hydraulic control of the mean flow is indicated by a region supercritical to long gravity waves in the dense layer located approximately $100 \mathrm{~km}$ downstream of the sill in both model and observations. In addition, despite the differences in surface forcing, both model and observations exhibit similar transitions from mostly barotropic flow at the sill to a bottom-trapped baroclinic flow downstream, indicating the dominant role of the overflow in determining the full water column dynamics. INDEX TERMS: 4255 Oceanography: General: Numerical modeling; 4211 Oceanography: General: Benthic boundary layers; 4219 Oceanography: General: Continental shelf processes; 4520 Oceanography: Physical: Eddies and mesoscale processes; 4568 Oceanography: Physical: Turbulence, diffusion, and mixing processes; KEYWORDS: overflow entrainment, process model, barotropic transport, deep water formation, rotating hydraulic control, eddy generation

Citation: Käse, R. H., J. B. Girton, and T. B. Sanford, Structure and variability of the Denmark Strait Overflow: Model and observations, J. Geophys. Res., 108(C6), 3181, doi:10.1029/2002JC001548, 2003.

\section{Introduction/Background}

[2] Because of its key role in the ventilation of the deep oceans, contributing about half of the source that later becomes North Atlantic Deep Water, the Denmark Strait Overflow (DSO) between Greenland and Iceland (see Figure 1) has been the subject of a number of past observational programs [Worthington, 1969; Ross, 1978; Aagaard and Malmberg, 1978; Dickson and Brown, 1994]. Most of these studies were based around moored current meter arrays of varying extent and duration.

[3] The combined effects of strong, deep currents, large vertical and lateral shears, energetic variability and complicated topography present challenges to obtaining representative observations and making firm conclusions. Nevertheless, after repeated studies, including several mul-

Copyright 2003 by the American Geophysical Union. 0148-0227/03/2002JC001548 tiyear current meter deployments, certain features have become evident. The Strait's width is large compared to the internal Rossby radius of $\sim 10 \mathrm{~km}$, making rotational effects important, and the dense deep layer is banked against the northwestern slope. At the sill, the overflow contains both strong mean and fluctuating components, and can reach instantaneous speeds of $1.4 \mathrm{~m} \mathrm{~s}^{-1}$ or more with $1.0 \mathrm{~m} \mathrm{~s}^{-1}$ speeds occurring regularly [Worthington, 1969].

[4] Rapid variation in overflow transport near the sill occurs in pulses with periods of $2-5$ days [Ross, 1984]. These pulses appear to possess consistent characteristics, including increased along-channel velocity, a thickening of the dense bottom plume layer and often a strong overlying core of low-salinity water. Satellite IR measurements of surface temperature have shown a dramatic train of cyclonic eddies directly over the path of the DSO along the coast of Greenland [Bruce, 1995]. These eddies appear to be a surface manifestation of the variability in the deep plume, an interpretation supported by laboratory experiments showing the 


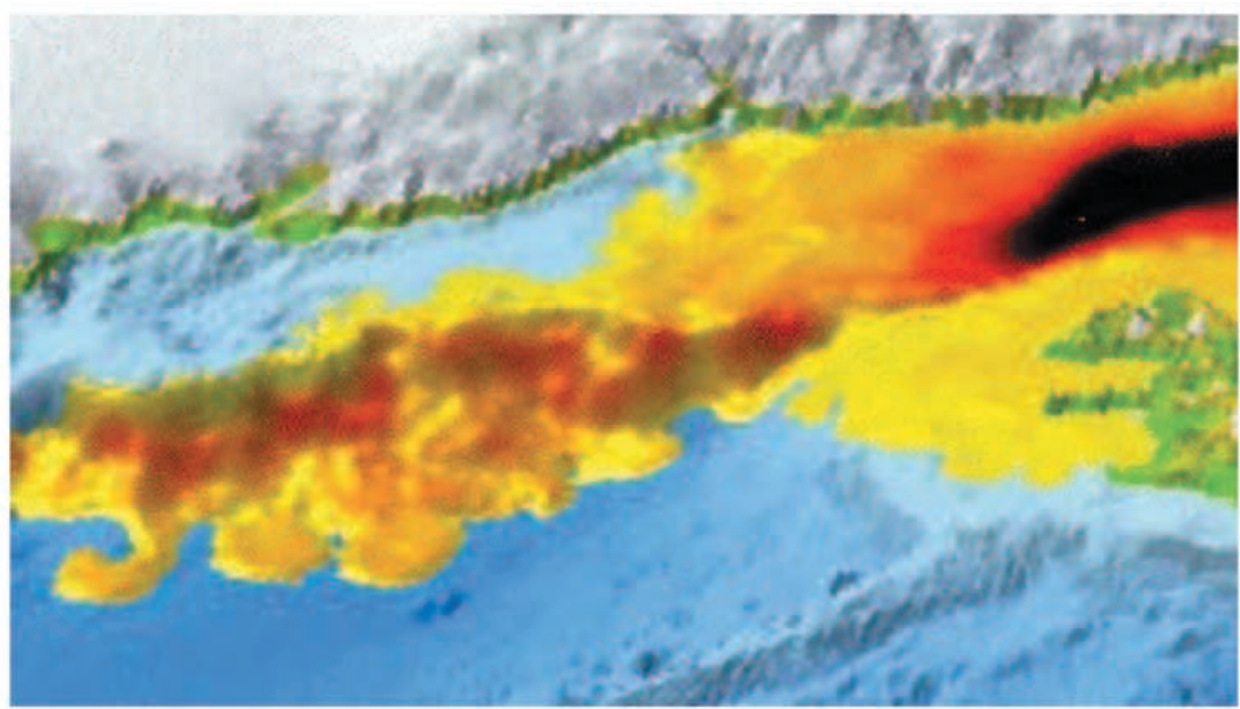

Figure 1. Aerial view of simulated overflow. Iceland is on the right margin, and Greenland is at the top. Yellow/red/black coloring (in increasing order) indicates the thickness of the overflow layer of dense water, with the greatest thickness in the northern basin reservoir. Green represents the coastline.

generation of strongly barotropic vortices by dense bottom water flow on a slope [Whitehead et al., 1990].

[5] Over a suitable averaging period (a week or more), the DSO appears to be steady, carrying an estimated $2.9 \mathrm{~Sv}$ of recently ventilated, cold water into the main basin of the North Atlantic. This transport is increased through entrainment over the first $150 \mathrm{~km}$ of descent from the sill to approximately 5.2 Sv [Dickson and Brown, 1994]. Seasonal and interannual variability have, so far, been too weak to be detected. However, recent efforts have focused on the possibility of connections between the overflow and convective processes in the Nordic Seas, possibly related to decadal forcing by the low-frequency components of the North Atlantic Oscillation [Bacon, 1998; McCartney et al., 1998; Dickson et al., 1999, 2002]. Some models have suggested that even decadal atmospheric variability may manifest itself more in regional water mass volume changes than in overflow variability [Mauritzen and Hakkinen, 1999] and that timescales of order 50 years or more are needed before overflow changes will become apparent. If correct, this hypothesis of overflow nonresponsiveness is likely to depend on the topographic limitation of exchanges across the Greenland-Scotland ridge, which could be quite sensitive to model-dependent effects including resolution and sub-grid-scale parameterizations of friction and mixing.

[6] The topographic control of rotating exchange flows has received substantial attention [Whitehead et al., 1974; Gill, 1977; Pratt and Lundberg, 1991; Killworth and MacDonald, 1993], and these theories can be applied (up to a point) in the Denmark Strait. Although a complete budget requires the inclusion of flows on the opposite side of Iceland, the local dynamics in the Denmark Strait can be approximated reasonably well as a single-layer reduced gravity outflow (with rotation producing a substantial amount of interfacial tilt or even separation of the dense layer from one wall of the strait). The layer of dense water from the Nordic Seas flows out rapidly while the thick upper layer flows in gradually and is probably of lesser dynamical importance. Hydraulic solutions of this form, however, tend to predict transports that are too large [Whitehead, 1989]. This discrepancy may be related to the neglected effects of friction, multiple layers or unsteady flow, or may simply be due to the need for the inclusion of an accurate bathymetry, as considered by Borenäs and Nikolopoulos [2000]. Certain features of these single-layer solutions, including the transition of flow from the left-hand to right-hand wall while approaching the sill, and the general shape of the density interface so produced, do appear to have a correspondence to the flow in the Denmark Strait, although the differences predicted by alternative theories [e.g., Rydberg, 1980], have not been easy to extract from previous observations.

[7] The processes affecting the dense water in and immediately after its transit through the strait have the greatest implications for large-scale water mass and tracer distributions. The magnitude and location of entrainment play a role both in the ultimate characteristics of the product water mass and in the sink-driven circulation of the layers entrained. The rate of descent of the dense water across topography can influence both the water masses and topographic features encountered. The evolution of the descending plume has been investigated through a hierarchy of techniques, beginning with simple one-dimensional reduced gravity "stream tube models" in which parameterizations of friction and entrainment based on mean plume velocity, thickness, and density are used to predict the plume's path and along-stream changes [Smith, 1975; Killworth, 1977; Price and Baringer, 1994]. Recent theoretical predictions for both the rate of descent [Killworth, 2001] and net entrainment [Holland et al., 2002] have been proposed, based in part on attempts to close turbulent energy budgets. While the assumptions underlying each of these energy-based methods may not always be met completely, the predictions do provide testable quantities to examine in models and observations.

[8] The source of the rapid variability in the overflow is also of interest, both for its effect on the hydraulic theories 
mentioned above and also for the potential of the eddies so generated to stir and spread the overflow waters, modifying both the entrainment and path of the plume. An analytical two-layer, quasi-geostrophic model for linear baroclinic instability in the Denmark Strait produces unstable motions at wave numbers and frequencies similar to those observed [Smith, 1976]. However, the surface eddies and rapid plume descent suggest strongly nonlinear processes for which the linear theory can only begin to provide explanation. Further complication is provided by recent observations that have suggested the presence of a narrow barotropic jet near the sill with the potential for instability growth rates comparable to the baroclinic theory [Fristedt et al., 1999]. In addition baroclinic instability could be occurring downstream in the along-slope portion of the plume [Swaters, 1991; Jungclaus et al., 2001].

[9] More complex numerical models of various sorts [Jungclaus and Backhaus, 1994; Jiang and Garwood, 1996; Spall and Price, 1998; Krauss and Käse, 1998; Käse and Oschlies, 2000; Shi et al., 2001] have explored the effects of topography, background stratification and stratified outflows, each arriving at different explanations for the variability.

[10] The ocean modeling community has focused on the DSO as represented in several general circulation models of the North Atlantic, but transport estimates from these have not been in good agreement [Willebrand et al., 2001]. This is not too surprising, considering the coarse horizontal and vertical resolution of these models in the Strait region, as well as their inadequate parameterizations of bottom friction [Marotzke and Willebrand, 1996]. Although increased resolution is one obvious means to improve realism, an important facet of current work is the search for improved parameterizations of near-bottom flows to allow the reasonable rendition of overflow-type processes in low-resolution simulations [Beckmann and Döscher, 1997; Killworth and Edwards, 1999]. Such parameterizations are required for the realistic production of deep and bottom waters in the longduration integrations needed for climate and paleoceanographic studies.

[11] The Denmark Strait Overflow has received renewed observational attention. The Nordic WOCE, VEINS and the German SFB-460 programs have contributed much new information from shipboard and moored observations. During our research we have participated to some extent in each of these programs. With such a growing body of both observational and modeling results, it is becoming more and more possible to interpret to what extent a regional model of the maximum viable resolution really gives an adequate solution to the outstanding questions about the DSO. In particular, does it reproduce observed velocity and density fields? Does it yield realistic product waters and entrainment regions? Are the leading-order dynamics comparable to those observed? Conversely, it is also our intention to use the model results to help in the interpretation of the (even now) sparse observations.

\section{A Process Study of the DSO}

[12] Despite the substantial volume of scientific work done in the Denmark Strait, direct velocity measurements have been sparse, consisting almost entirely of moored current meters at a few locations and depths. A better sampling of the horizontal and vertical structure of velocity is needed in order to identify the effects of bottom friction, entrainment stress, internal wave drag, potential vorticity conservation and hydraulic control. In particular, the interface between the dense plume and the overlying water, where vertical shear and entrainment are maximized, is of critical importance but is often deeper than the range of shipboard ADCP measurements.

[13] We participated on four cruises in the DSO region over a 3-year period. Our strategy was to conduct highresolution observations in various segments of the overflow in different years and combine them into a comprehensive description. The four cruises were (in order): August 1996, R/V Poseidon (Institut für Meereskunde, Kiel, Germany) cruise 222; June/July 1997, Poseidon 230; August/September 1997, R/V Aranda (Finnish Institute for Marine Research, Helsinki) VEINS cruise 12/1997; September 1998, Poseidon 244. We will henceforth refer to the cruises by year and ship name only. Only a subset of the Aranda 1997 sections are included in our combined data set, the remainder having been described by Rudels et al. [1999]. Complementing our snapshot observations of the highly variable DSO, we have made extensive examination of a highresolution process model operating with realistic bottom topography and a buoyancy-driven flow with parameters appropriate to the DSO.

\subsection{Observational Methods}

[14] Extensive observations of temperature and salinity from ship-lowered CTD were made during hydrographic studies aboard all four cruises. These studies, along with the ADCP observations obtained at the same time, nicely establish the context in which our rapid studies of velocity and water properties are placed.

[15] In addition, on the Poseidon 1998 cruise a rapid survey of the velocity and hydrographic variability was made using expendable instruments, including XCP (eXpendable Current Profiler) for velocity and temperature [Sanford et al., 1982] and XCTD (eXpendable CTD) for temperature and salinity. The expendable instrumentation allowed for faster sampling and a greater opportunity to conduct measurements in a region where rough weather often limits ship operations. In addition, the XCP is able to measure velocity to closer than $1 \mathrm{~m}$ from the bottom, yielding important boundary layer characteristics including shear stress $\left(\tau_{b}\right)$, estimated by fitting a logarithmic profile to the near-bottom velocity [Johnson and Sanford, 1992]. Initial results from this survey have been described by Girton et al. [2001], Girton [2001], and Girton and Sanford [2003]. The three sections from the Aranda 1997 cruise used here also included XCP measurements but at the pace of standard ship-lowered surveying.

\subsection{High-Resolution Model}

[16] We consider the terrain-following coordinate model of Käse and Oschlies [2000] (hereinafter referred to as KO), to which we direct the reader for additional details. Bathymetry is derived from the 5-min ETOPO5 database, interpolated to a $\sim 4 \mathrm{~km}$ grid oriented along the axis of the strait. (See Girton [2001] for a discussion of Denmark Strait region differences among ETOPO5, Poseidon echo 

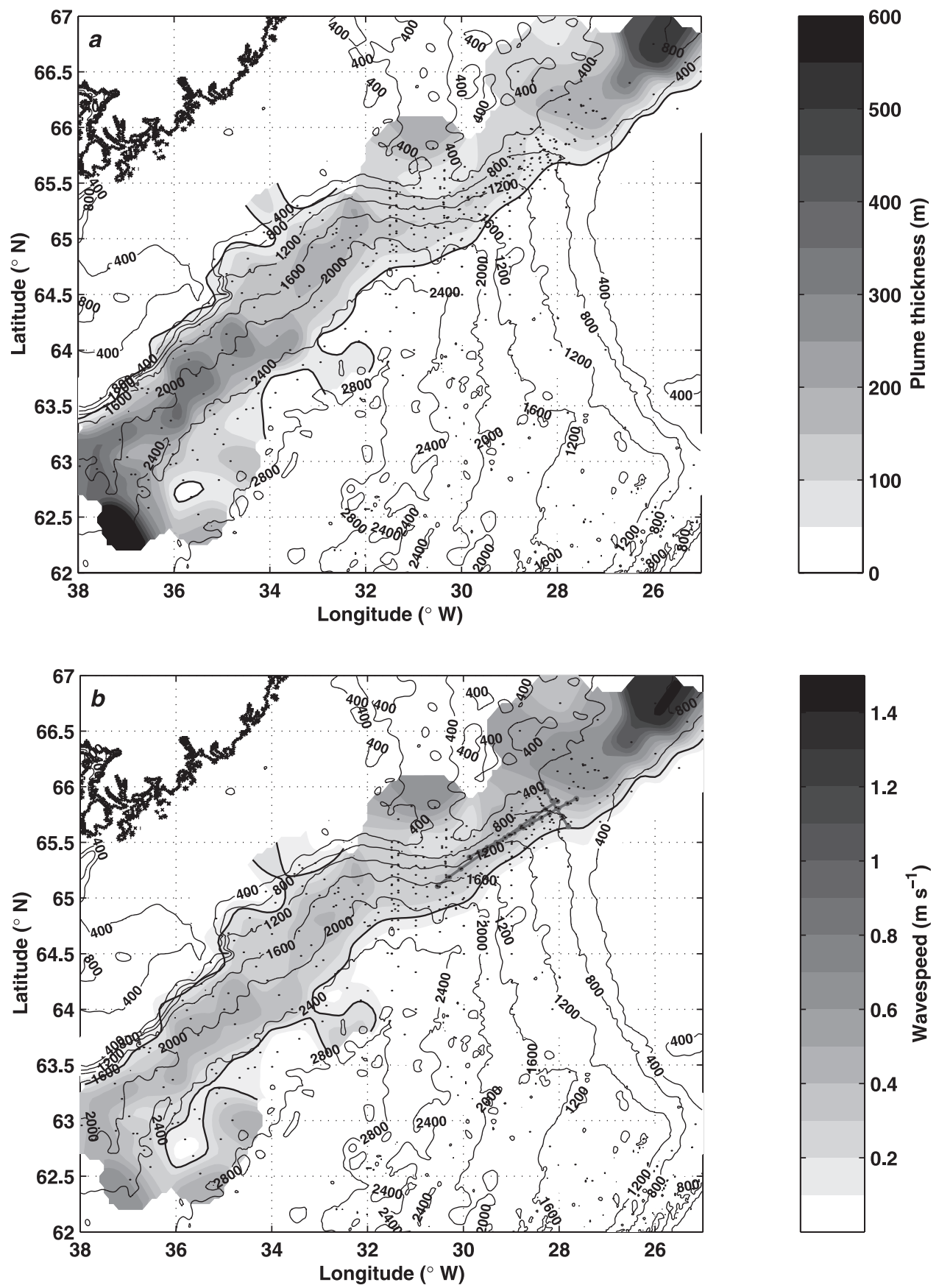

Figure 2. Overflow layer $\left(\sigma_{\theta}>27.81 \mathrm{~kg} \mathrm{~m}^{-3}\right)$ (a) thickness $(D)$ and (b) gravity wave speed $\left(c_{w}=\sqrt{g^{\prime} D}\right)$ from the combined 1996-1998 Poseidon/Aranda data set. Straight gray lines in Figure 2b indicate locations of sections shown in Figures $4 \mathrm{a}, 5 \mathrm{a}$, and $5 \mathrm{~b}$. Small dots indicate locations of profiles. Thick black lines (50 m and $0.2 \mathrm{~m} \mathrm{~s}^{-1}$ contours) emphasize the boundaries of the overflow water. Bathymetry in meters from Smith and Sandwell [1997] is shown by thin solid lines.

sounder measurements and the 2-min database of Smith and Sandwell [1997].) Only one dynamically active tracer is included, temperature, which uniquely determines density through the relation:

$$
\sigma_{\theta}\left(\mathrm{kg} \mathrm{m}^{-3}\right)=28.0-0.08 \times T\left({ }^{\circ} \mathrm{C}\right)
$$

Initially, the model contains only warm $\left(5^{\circ} \mathrm{C}\right)$ water south of the sill and in the upper $150 \mathrm{~m}$ north of the sill with temperature $-1{ }^{\circ} \mathrm{C}$ below. Mixing is included through a biharmonic horizontal diffusivity (tracer and momentum) of $2 \times 10^{9} \mathrm{~m}^{4} \mathrm{~s}^{-1}$, harmonic vertical diffusivity of $10^{-3} \mathrm{~m}^{2} \mathrm{~s}^{-1}$ and simple convective adjustment.

[17] Throughout this paper we will primarily consider the resulting flow on days $17-32$ after the initial "dam break," during which time the flow has achieved a quasi-steady state over the region of initial descent but the effects of the finite basins (diminishing upstream reservoir height and filling 
downstream basin) have not yet become dominant. Unless otherwise specified, we will be using $2.5^{\circ} \mathrm{C}\left(27.8 \mathrm{~kg} \mathrm{~m}^{-3}\right)$ as the delimiting isotherm (isopycnal) for bulk averages of the overflow and $5^{\circ} \mathrm{C}$ as the "background" for defining a density anomaly (i.e., $\rho^{\prime}(\mathrm{T})=\sigma_{\theta}(\mathrm{T})-\sigma_{\theta}\left(5^{\circ} \mathrm{C}\right)$ ). This is primarily for ease of comparison with the observations, although for certain dynamical processes (e.g., entrainment) other bounding isotherms might be more useful.

[18] Unlike the results presented in $\mathrm{KO}$, the model runs discussed here employed a quadratic drag law:

$$
\tau_{\mathbf{b}} / \rho=C_{D}|\mathbf{U}| \mathbf{U}
$$

where $\mathbf{U}$ is the velocity of the bottom layer of the model and $C_{D}$ is a constant equal to $1 \times 10^{-3}$ in the primary model run we discuss (denoted "low friction"). We will also make some comparison with results from a run with $C_{D}=3 \times$ $10^{-3}$ (denoted "high friction"). Observed values of $\tau_{b}$ from near-bottom velocity profiles have been compared with bulk overflow layer velocities to give a best fit $C_{D}$ very close to $3 \times 10^{-3}$, although the scatter in individual measurements is quite large [Girton and Sanford, 2003].

\subsection{Overflow Character in Model and Observations}

[19] Comparison with the database of observations reveals that the essential characteristics of the overflow have been successfully simulated in the model. Figure 2 depicts the observed descent and spread of the plume as defined by: a) the thickness $(D)$ of the anomalous water, determined by the height of the $27.81 \mathrm{~kg} \mathrm{~m}^{-3}$ isopycnal above the bottom, and b) the integrated density anomaly relative to a mean background profile $\tilde{\rho}(z)$ (presented as a wave speed, $c_{w}=\sqrt{g^{\prime} D}=\sqrt{g \int_{z \omega^{\prime}}^{z_{27.81}} \rho^{\prime} d z}$ where $\rho^{\prime}=\rho-\tilde{\rho}$ ) for water denser than $27.81 \mathrm{~kg} \mathrm{~m}^{-3}$. The differences between the thickness and wave speed versions of the plume can be attributed primarily to the entrainment of lighter backgroundwater which can increase thickness and overflow volume transport without affecting the integrated density anomaly. An additional increase in thickness (Figure $2 \mathrm{a}$; dark patch at the southern edge of the plume) is related to the presence of slightly denser backgroundwater in the deeper parts of the plume, reducing the utility of the 27.81 $\mathrm{kg} \mathrm{m}^{-3}$ definition in this region.

[21] The observed mean plume can be compared with Figure $3 \mathrm{a}$, the time mean wave speed from days 17-32 of the model. However, it is important to note that the model does not contain a background stratification, which will tend to reduce the integrated density anomaly during descent. The apparent agreement between Figures $2 \mathrm{~b}$ and $3 \mathrm{a}$ may be the result of a fortuitous combination of $g^{\prime}$ decrease due to background stratification and $D$ increase due to slowing and thickening, neither of which is duplicated in the model.

[22] The observations show the dense water banked against the Greenland slope and descending after passing south of the Dohrn Bank (at roughly $65.7^{\circ} \mathrm{N}, 30^{\circ} \mathrm{W}$ ). From $29^{\circ} \mathrm{W}$ to $32^{\circ} \mathrm{W}$ (a distance of about $175 \mathrm{~km}$ ) the core descends from 800 to $2000 \mathrm{~m}$. During the initial descent, the offshore edge of the dense water essentially follows the talweg, or deepest part of the channel. The filling to the talweg may at least partly result from the strong bottom friction in individual eddies leading to "Ekman drainage" [Lane-Serff and Baines, 1998]. After the edge reaches about
$2000 \mathrm{~m}$, the plume proper becomes separated from the Iceland slope, while isolated patches of dense water appear further downstream at depths as great as $2800 \mathrm{~m}$. These patches may be related to an instability of the sort outlined by Jungclaus et al. [2001] or may be simply a result of the offshore edge of the plume reaching its settling depth within the background stratification.

[23] The modeled mean plume (Figure 3a) exhibits essentially the same behavior as the observations, with a somewhat less rapid initial descent across topography. This descent will be discussed in more detail in section 3.5. A subsequent deep spreading of the plume is apparent in both the southwest corner of Figure $3 \mathrm{a}$ and at the left-hand edge of the Figure 1 perspective view. In fact, an eddy or subplume-like character is suggested by both the model and the observed deep patches (Figures 1 and 2), indicating similarity with the results of both Jungclaus et al. [2001] and Jiang and Garwood [1996]. The reader is, however, cautioned to note the locations of measurement points (small dots) in Figure 2 and to be aware of the possible effects of the Gaussian smoothing on the appearance of the fields.

[24] The velocity and density structure of the overflow in cross section is shown in Figure 4. Figure 4a, from Poseidon 1998, shows the thick dense layer banked against the Greenland slope along with strong barotropic velocities $\left(0.8 \mathrm{~m} \mathrm{~s}^{-1}\right)$ and strong lateral shears $(\Delta v / \Delta x \sim f / 2)$. Figure $4 \mathrm{~b}$, from the model, exhibits similar features to those seen in Figure 4a, albeit with smaller barotropic velocities $\left(0.6 \mathrm{~m} \mathrm{~s}^{-1}\right)$ and shears. As the overflow progresses downstream (not shown) the cross-sectional character becomes more baroclinic, with much of the velocity confined to the dense near-bottom layer. Nevertheless, a strong barotropic velocity component persists at the onshore edge of the plume, mostly confined to the vicinity of the Greenland shelf break.

\subsection{Variability in Model and Observations}

[25] The model, like the observed fields, contains considerable variability superposed on the mean flow. The variability consists of strong barotropic eddies occasionally interrupting the overflow [Käse and Oschlies, 2000]. For the most part, the eddies appear as domes of dense water that follow the isobaths of the continental slope and form, in average, the path of the time mean plume. This is distinct from a second form of eddy activity that fills the deeper portions further downstream. Figure $3 \mathrm{~b}$ is a snapshot (day 32) from the model showing several discrete eddies of 30$50 \mathrm{~km}$ in diameter and spaced $70-100 \mathrm{~km}$ apart. Ekman drainage may also contribute to the filling of the deeper parts of the model basin, although some of the dense water on the offshore plume edge (e.g., the patch at $65.2^{\circ} \mathrm{N}$, $29.0^{\circ} \mathrm{W}$ ) appears to have been simply been "left behind" after an eddy passed by.

[26] Figures 5a and 5b are examples of along-stream density sections from the 1997 Aranda and the 1998 Poseidon cruises, respectively. On the $27.8 \mathrm{~kg} \mathrm{~m}^{-3}$ contour, the Aranda section exhibits thin and fast $\left(>0.7 \mathrm{~m} \mathrm{~s}^{-1}\right)$ overflows on the steep slopes (centered at 160 and $65 \mathrm{~km}$ ) alternating with thick domes, while the Poseidon 1998 section has much thinner but more uniform velocity $\left(>1 \mathrm{~m} \mathrm{~s}^{-1}\right)$ but without the prominent domes until near the ends of the section. Both sections show the same pattern 


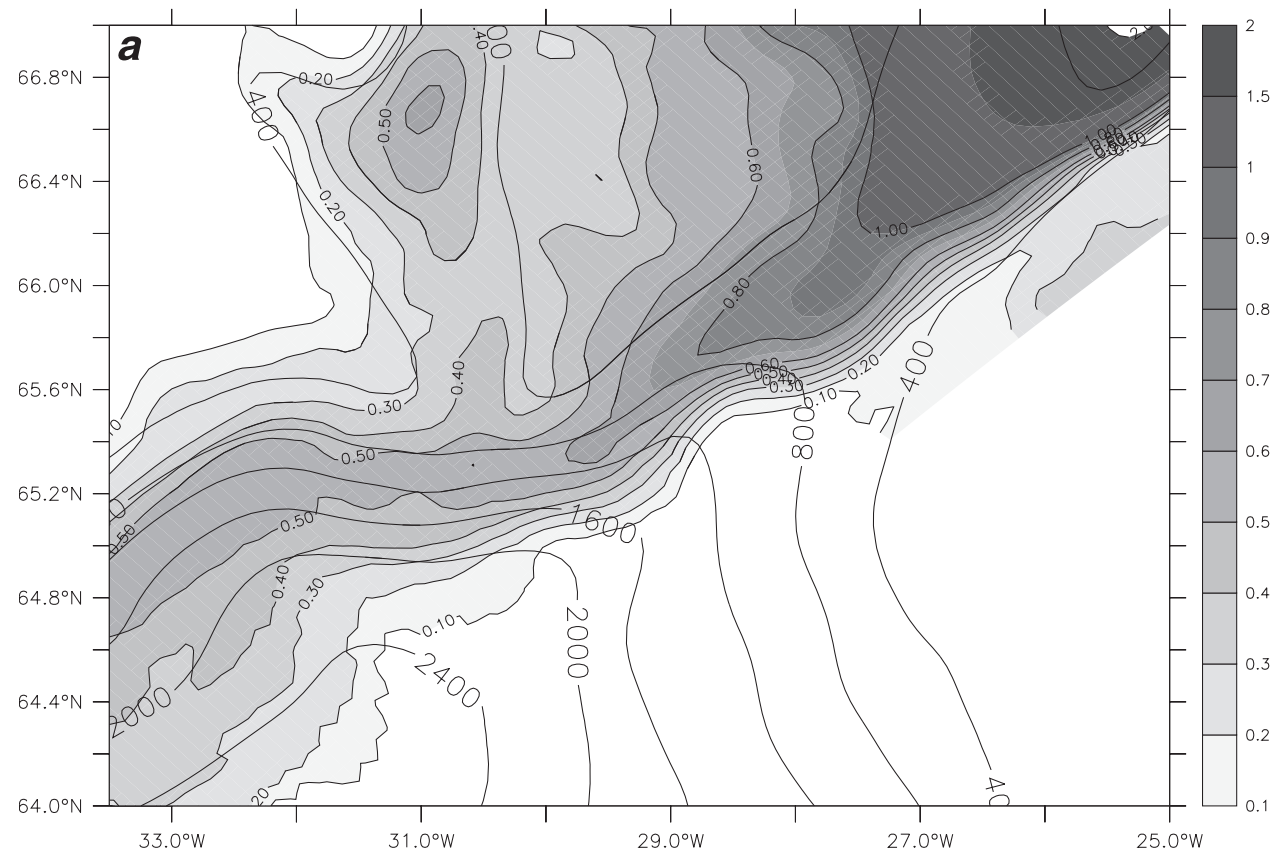

16-day mean of model characteristic speed

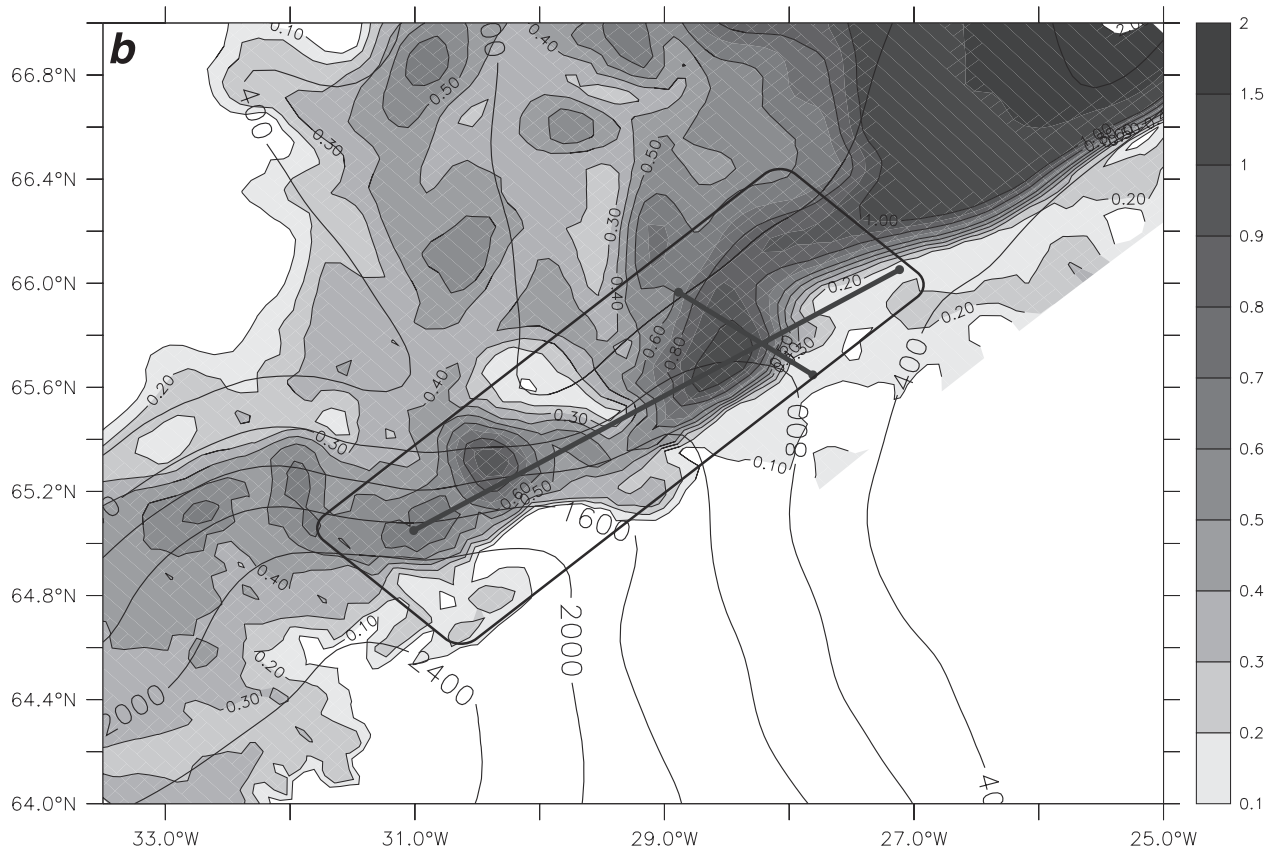

snapshot of model characteristic speed

Figure 3. Model wave speed $\left(c_{w}\right.$, in $\left.\mathrm{m} \mathrm{s}^{-1}\right)$ from (a) mean over days 17-32 and (b) snapshot at the end of day 32. Thick lines in Figure $3 \mathrm{~b}$ indicate locations of sections shown in Figures $4 \mathrm{~b}$ and $5 \mathrm{c}$. The rounded box in Figure $3 \mathrm{~b}$ indicates the region shown in the eddy time sequence, Figure 8. Model bathymetry in meters (thin solid contours) is derived from ETOPO5.

of thin, fast overflow layers on the leading (SW) edge of the domes and brief periods of almost total overflow cutoff on the immediately trailing edge. The system is clearly not periodic, as evidenced by the nonuniform spacing of the domes, but a reproducible sequence of similar events does appear to be occurring.
[27] Figure 5c is a snapshot from day 32 of the model simulation, showing density anomalies that are comparable to those in the observed sections. In particular, the section contains a prominent dense water dome, a broad region of thin fast overflow and brief intervals of almost total cutoff. 

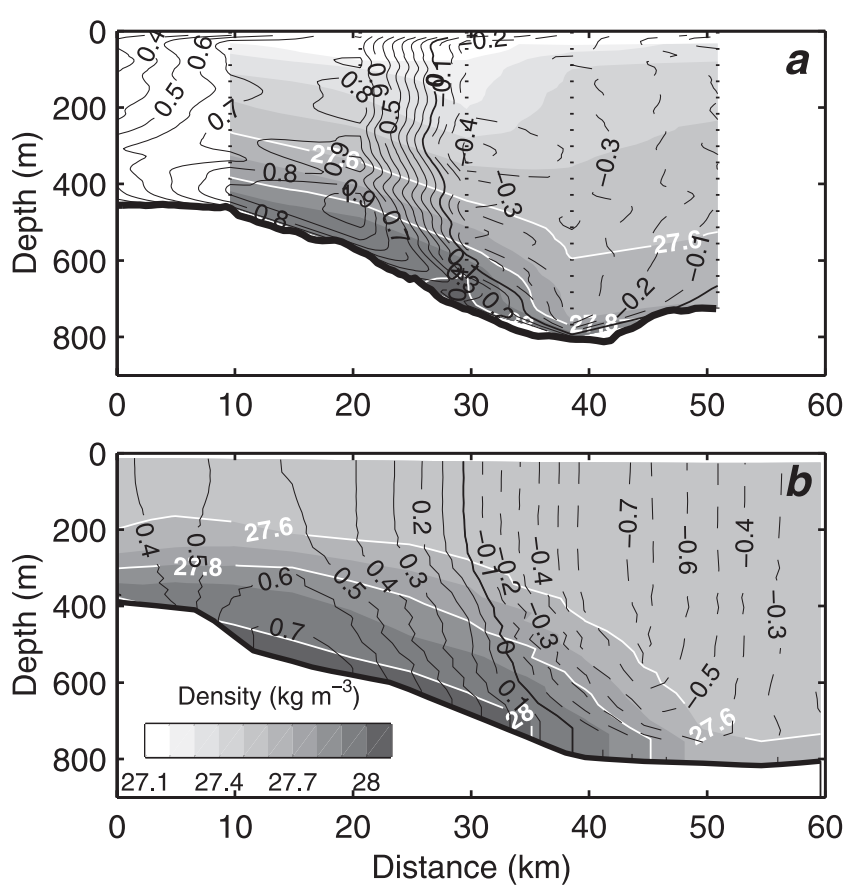

Figure 4. Cross-stream section of density (shaded) and along-stream velocity (contours in $\mathrm{m} \mathrm{s}^{-1}$; dashed lines indicate flow to the northeast, away from the viewer) at approximately the Ross current meter array location from (a) Poseidon 1998 cruise and (b) model snapshot (day 32).

[28] There is much variability to the plume thickness in the observations and model. Figure 6 shows the histogram of thickness at various cross sections for the full 16-day period (days 17-32). The sections are (a) at the sill, (b) where the plume is rapidly descending, and (c) farther downstream where the eddies are fully developed. One sees that near the sill the plume thickness is centered around 300 $m$. In the descent, there is large variability in plume thickness. Further downstream the plume is dominantly thin, punctuated by eddies of various thickness, leading to a tail in the distribution extending from 200 to $400 \mathrm{~m}$.

\section{Discussion of Overflow Dynamics}

\subsection{Transport Mode}

[29] As mentioned above, the transport of dense $\left(\sigma_{\theta}>\right.$ $27.8 \mathrm{~kg} \mathrm{~m}^{-3}$ ) water occurs in essentially barotropic currents near the Denmark Strait sill and undergoes a transition to bottom-trapped baroclinic flow as the dense water descends the Greenland slope. This behavior appears in both the modeled and observed velocity fields. We have decomposed the transport below the $27.8 \mathrm{~kg} \mathrm{~m}^{-3}$ isopycnal into a barotropic part $\left(Q_{B t}\right)$, attributable to the depth-averaged velocity $(\bar{v})$ and a baroclinic remainder $\left(Q_{B c}\right)$ :

$$
Q_{B t}=\int_{z_{b o t}}^{z_{27.8}} \bar{v} d z=\bar{v} D
$$

and

$$
Q_{B c}=\int_{z_{b o t}}^{z_{27.8}} v^{\prime} d z
$$

where $\bar{v}+v^{\prime}=v$, the total velocity, and $Q_{B t}+Q_{B c}=Q$, the total dense water transport.

[30] Figure 7 shows this decomposition as a function of distance from the sill. While a robust trend is not always perfectly clear from the observations (symbols), the observed transports do tend to track the model means (solid lines), with $Q_{B t}$ decreasing from the sill while $Q_{B c}$ increases. The partitioning becomes approximately equal in the region $50-100 \mathrm{~km}$ from the sill in both model and observations. Transport variability (shaded at the $2 \sigma$ level from the model) tends to scale with mean transport, with the model display-
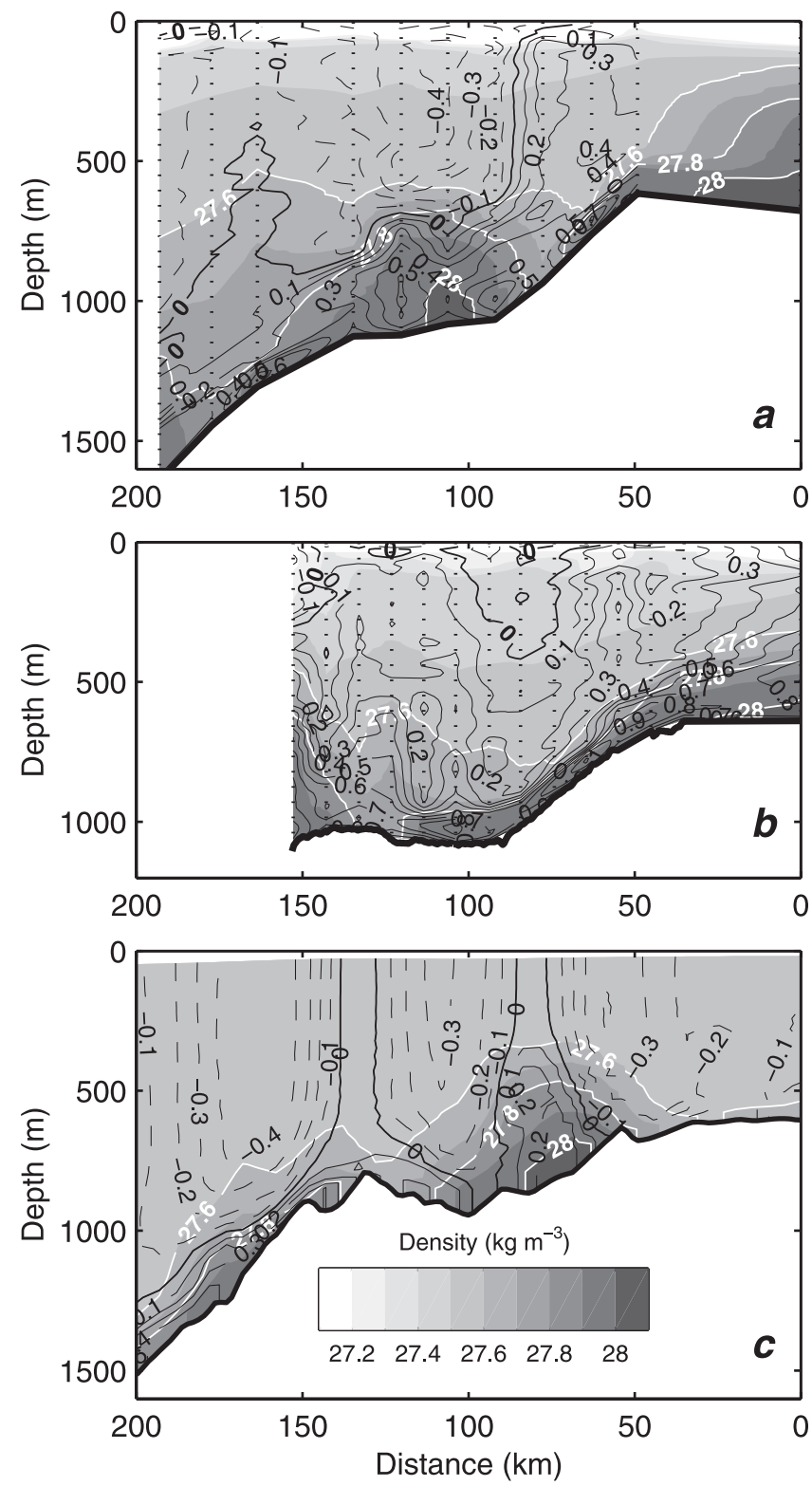

Figure 5. Along-stream sections of density and alongstream velocity from (a) Aranda 1997 and (b) Poseidon 1998 cruises, as well as (c) a snapshot from the model (end of day 32). Bathymetry shown is from linear interpolation from station positions only (Figure 5a); continuous alongtrack echo sounder data (Figure 5b); and bilinear interpolation to the section line shown in Figure 3 from the model grid (Figure 5c). 


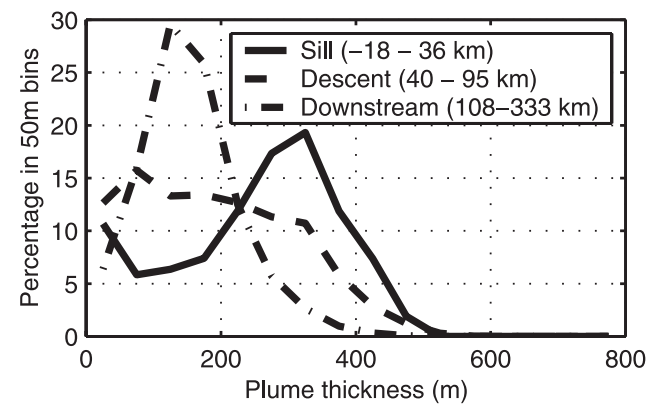

Figure 6. Overflow thickness probability distributions from three regions in the model.

ing larger than observed $\mathrm{Bt}$ variability and smaller $\mathrm{Bc}$ variability. Interestingly, the fraction of transport attributable to the barotropic currents $\left(Q_{B} t Q\right.$, Figure $\left.7 \mathrm{~b}\right)$ seems to show a better model-observations agreement than the transports themselves, possibly indicating a robust dynamical effect. As described in $\mathrm{KO}$, the maximal hydraulic transport predicted by the formula $Q=\frac{g^{\prime} H_{0}^{2}}{2 f}$ [Whitehead et al., 1974] matches well with the model's peak instantaneous transports at the sill (where the $H_{0}$ used is the height of the interface above the sill, taken upstream of the sill at approximately $66.4^{\circ} \mathrm{N}, 26.4^{\circ} \mathrm{W}$ ), while the mean sill transport is only $58 \%$ of the hydraulic prediction.

\subsection{Eddies}

[31] DSO variability, though complex, has a number of well-defined and repeatable characteristics including timescales, spatial patterns and correlations between velocity and density. Nevertheless it is not entirely straightforward to attach a definitive name (together with phenomenological implications) to this variability, and so claims of "domes," (bottom-trapped dense water anomalies), "pulses," (episodes of increased transport) "waves" (propagating features) and "eddies" (vortical motions) have all been presented in the literature.

[32] A prominent feature of satellite SST images of the Denmark Strait is the presence of spiral structures, generally referred to as eddies [Bruce, 1995; Munk et al., 2000]. The relationship between these SST-detected eddies and subsurface structure has been difficult to investigate with simultaneous observations. The model, however, provides the opportunity for such an investigation.

[33] One caveat regarding the model results is the lack of an overlying stratification, leading to cleaner two-layer dynamics than might actually exist in the DSO region. The magnitude of this discrepancy can be estimated from the thickness of the upper layer relative to the Taylor column height $\frac{f L}{N}$. For a typical (minimum) eddy diameter of $20 \mathrm{~km}$, this height varies from $1300 \mathrm{~m}$ in the upper water column (above $1000 \mathrm{~m}$ depth) to over $3000 \mathrm{~m}$ in the deep Irminger Sea, indicating that even in the presence of stratification the water column above the dense overflow will behave primarily as a single layer.

\subsubsection{Eddy Generation}

[34] Figure 8 shows the process of eddy generation through the time evolution of the model's thickness and velocity at intervals of 16 hours for a vertical average over the layer defined by $\sigma_{\theta}>27.8 \mathrm{~kg} \mathrm{~m}^{-3}$. It shows the development of a cyclonically rotating dome of dense water from an initially thin overflow patch with down-slope directed velocity. Note that this sense of rotation around a dense dome is the opposite of what would be expected in a purely reduced gravity flow with an inactive upper layer. Such behavior can only occur with a strong barotropic component to the velocity and an accompanying sea surface depression.

[35] The resulting dome becomes elongated in the alongslope direction and begins to propagate toward "topographic west" as another eddy forms behind it. This process occurs at approximately $100 \mathrm{~km}$ from the sill, in a region with bottom depths of $600-800 \mathrm{~m}$, producing an eddy spacing of about $100 \mathrm{~km}$. The propagation speed of the eddies is $\sim 0.4 \mathrm{~m} \mathrm{~s}^{-1}$, about half of the long gravity wave speed predicted by $c_{w}$ (Figure 3 ).

\subsubsection{SSH Versus Overflow}

[36] The barotropic component of the eddy velocities described above must be related to gradients in sea surface height (SSH) producing surface currents that mimic or mirror the deep isopycnal slopes. This equivalent barotropic character is demonstrated in the model by a strong correlation between low SSH and high plume thickness (Figure 9). Over strong eddies one finds the largest sea surface depressions, with the pressure contribution from the SSH anomaly $(\rho g \Delta \eta)$ outweighing that from the dense dome $\left(\rho^{\prime} g \Delta D\right)$ by
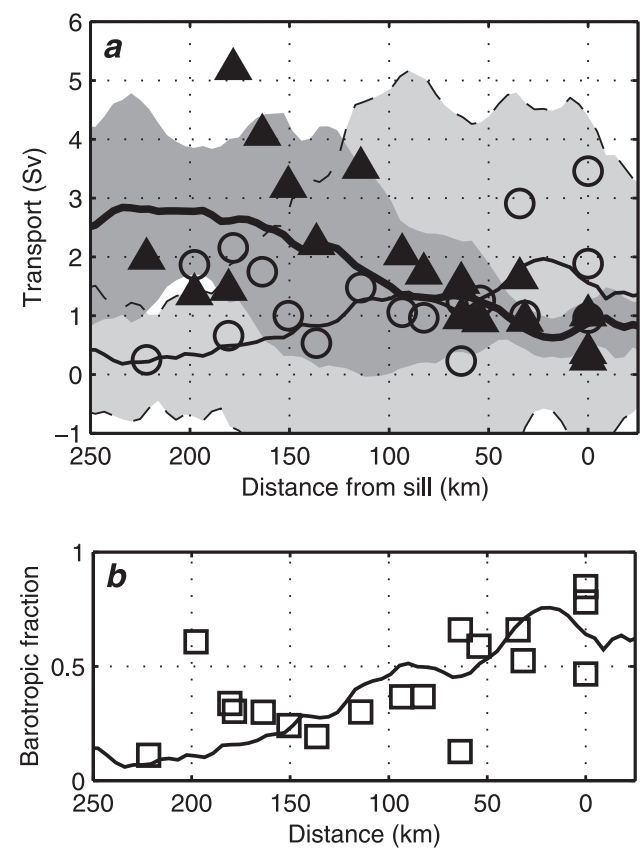

Figure 7. (a) Relative magnitudes of barotropic transport $\left(Q_{B}\right.$ : thin line is model mean, and open circles are observations) and baroclinic transport $\left(Q_{B c}\right.$ : thick line is model mean, and solid triangles are observations) versus distance. $2 \times$ RMS variability in the model's transport is indicated by shading (light for the barotropic, dark for the baroclinic). (b) The fraction of the total dense water transport attributable to the barotropic velocity alone, indicating a reasonable agreement between the model (solid line) and observations (squares). Note that distance from the sill increases to the left, as if viewing the coast of Greenland from the south-southeast. 


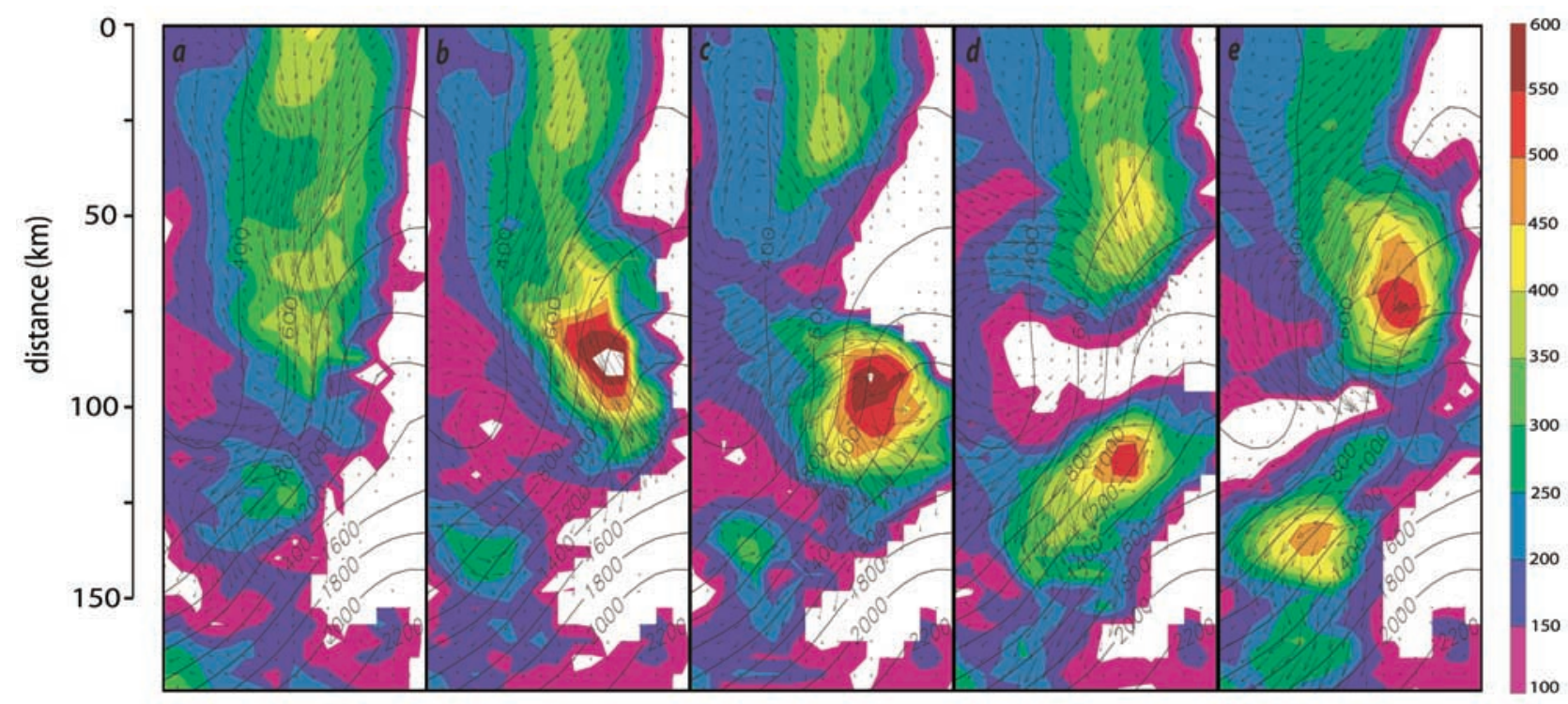

Figure 8. Sequence of snapshots of thickness (color scale in meters) and transport (arrows) for the dense overflow layer $\left(\sigma_{\theta}>27.8 \mathrm{~kg} \mathrm{~m}^{-3}\right)$ spaced 16 hours apart at (a) 29.3 , (b) 30 , (c) 30.7 , (d) 31.3 , and (e) 32 days from the "dam break." Solid contours show model bathymetry in meters.

$2: 1$ or more. The eddy velocity, then, is primarily barotropic, as previously stated.

[37] This surface-depth correlation may be related to that found in model runs by Käse et al. [2001] encompassing the entire North Atlantic basin. They observed that, in runs starting from a nonoverflow initial condition and forced by relaxation at the northern boundary, a band of surface depression moves into the domain along the overflow path. The depression follows the continental slope around the tip of Greenland and into the Labrador Sea boundary current, providing a possible mechanism for the cyclonic recirculation gyres observed there [Lavender et al., 2000].

\subsubsection{Eddies and Transport}

[38] A prominent consequence often attributed to the eddies is the production of the large variability observed in transport time series [Ross, 1984]. Exactly how this happens is not entirely clear, and so it is worth comparing the patterns of transport and vorticity variability in the model to investigate the process further. As mentioned earlier, the dominant contributor to dense water transport near the sill is the barotropic (depth-averaged) velocity, while the baroclinic component becomes more important downstream (beyond $100 \mathrm{~km}$ from the sill). While transport variability is seen close to the sill, the barotropic eddies are most evident right around this $100 \mathrm{~km}$ transition region, coincident with the descent of the dense bottom water layer, vortex stretching in the overlying layer and subsequent development of the baroclinic gravity current flow. Figure 10 shows this process in the form of a Hovmöller diagram of overflow transport (baroclinic and barotropic; see equations (4) and (3)) and barotropic vorticity $(\zeta=\nabla \times$ $\overline{\mathbf{v}})$. The upper two panels (a and b) show contours of section-integrated transport ( $Q_{B c}$ and $Q_{B}$, respectively) of dense $\left(\sigma_{\theta}>27.8 \mathrm{~kg} \mathrm{~m}^{-3}\right)$ water versus time and distance from the sill. The lower panel's contours are the maximum barotropic vorticity in each section. Starting from the sill $(0 \mathrm{~km})$, there is an immediate development of high-fre- quency ( $\sim 2$-day period) variability in the barotropic transport, and between 50 and $150 \mathrm{~km}$ there is a transition from $\mathrm{Bt}$ to $\mathrm{Bc}$ transport and variability. Beyond $150 \mathrm{~km}$, the speed of barotropic propagation (as determined by the slopes of features) appears to decrease to $\sim 0.15 \mathrm{~m} \mathrm{~s}^{-1}$, in contrast to the speeds of $0.25-0.5 \mathrm{~m} \mathrm{~s}^{-1}$ closer to the sill. Estimated baroclinic phase speeds drop from about $0.4 \mathrm{~m} \mathrm{~s}^{-1}$ in the steep descent region (where $Q_{B c}$ begins to dominate) to $0.25 \mathrm{~m} \mathrm{~s}^{-1}$ after $150 \mathrm{~km}$. Vorticity anomalies (Figure 10c), prominent in the $\mathrm{Bt}-\mathrm{Bc}$ transition region, are most correlated with the $Q_{B t}$ anomalies and show the same propagation speed decrease. A direct comparison is provided by a time series at $100 \mathrm{~km}$ from the sill (Figure 11), showing the coincidence between peaks in $Q_{B t}$ and $\zeta$ (as well as a weaker correlation with $Q_{B c}$ ). Note that there is an event at $\sim 240 \mathrm{~km}$ that seems to appear spontaneously, which seems to originate from the second form of eddy activity, likely

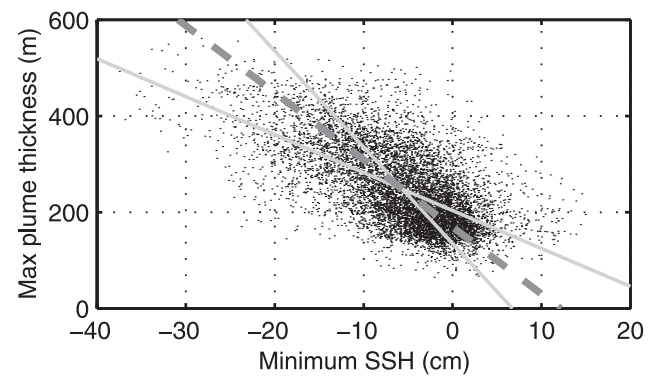

Figure 9. Correlation between overflow thickness (crosssectional maximum) and eddy sea surface height (SSH) depressions (cross-sectional minimum) from days 17 to 32 of the model run. Solid gray lines show the results of $x$ versus $y$ and $y$ versus $x$ least squares fitting, yielding slopes of 7.9 and $20.0 \mathrm{~m} / \mathrm{cm}$ (plume thickness change corresponding to SSH change). The average slope of $13.9 \mathrm{~m} / \mathrm{cm}$ is shown by the dashed line. 

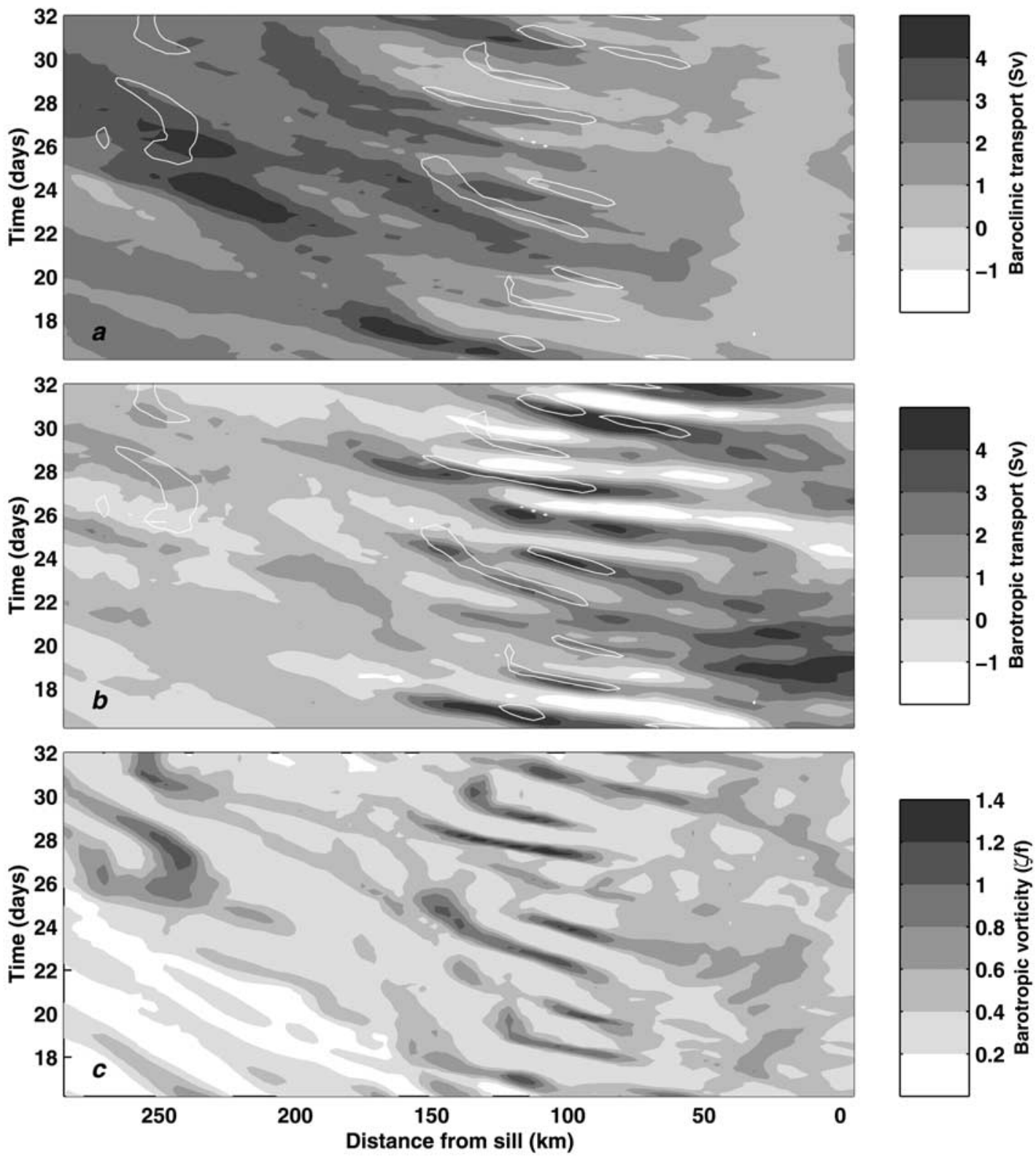

Figure 10. Propagation of transport pulses and eddies (vorticity anomalies) in the model. Panels contain (a) baroclinic $\left(Q_{B c}\right)$, (b) barotropic $\left(Q_{B t}\right)$ transport (integrated across the overflow), and (c) maximum barotropic vorticity $(\zeta)$ in each cross section. The 0.8 contour from Figure $10 \mathrm{c}$ has been reproduced in white on Figures 10a and 10b for reference.

related to baroclinic instability downstream [Jungclaus et al., 2001].

\subsection{Entrainment}

[39] From analysis of dilution rates in the Aranda 1997 and Poseidon 1998 data, Girton and Sanford [2003] report two distinct entrainment rates $\left(w_{e}\right)$ of $6 \times 10^{-5} \mathrm{~m} \mathrm{~s}^{-1}$ and $8 \times 10^{-4} \mathrm{~m} \mathrm{~s}^{-1}$ in the regions before and after $125 \mathrm{~km}$ from the sill, respectively. While the overflow variability restricts this observational analysis to broad regions, the mean temperature class transport fields from the model $\left(Q_{T}\right.$, indicating transport of all water colder than $T$ ) permit a more detailed analysis (Figure 12). At the same time, it is important to note that many processes believed to control entrainment in physical flows are not included in the model, and what we are labeling entrainment in the model is entirely due to horizontal and vertical diffusion, convective adjustment, and possibly even sigma coordinate advection. Nevertheless, these numerical schemes are designed to conserve mass and tracers and are widely used in simulating oceanic phenomena. We feel that a comparison of bulk results can be informative for comparison and future planning, if not a true study of a physical process.

[40] From the slopes of transport $\left(Q_{T}\right)$ versus distance $(\xi)$ lines, as well as the divergence of adjacent lines, it is possible to diagnose a number of features of the mixing 


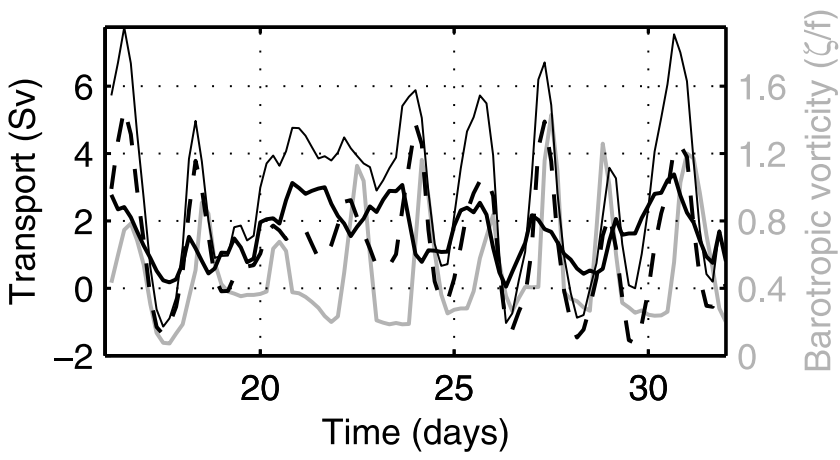

Figure 11. Time series at a location $100 \mathrm{~km}$ downstream of the sill. Total transport ( $Q$, thin black line) is decomposed into baroclinic $\left(Q_{B c}\right.$, thick black) and barotropic $\left(Q_{B t}\right.$, dashed) components. Maximum barotropic vorticity $(\zeta$, indicating the presence of eddies) is shown in gray.

and entrainment. For example, the entrainment velocity $\left(w_{e}\right)$ can be related directly to the slope:

$$
w_{e}=\frac{1}{W} \frac{\partial Q_{T}}{\partial \xi}
$$

where $W$ is the width of the overflow plume (seen from Figure $3 \mathrm{a}$ to be $\sim 40 \mathrm{~km}$ over at least the first $200 \mathrm{~km}$ from the sill). While this number can be calculated for any one of the $Q_{T}$ versus $\xi$ curves, it has the strongest meaning for the warmest isotherms less than $5^{\circ} \mathrm{C}$, since these best define the bounding line for the anomalous overflow water. Thus the $w_{e}$ across the $4.5^{\circ} \mathrm{C}$ isotherm represents entrainment into the majority of the plume. In fact, a substantial amount of additional fluid is entrained into the class colder than $4.9^{\circ} \mathrm{C}$ (not shown) which reaches $5 \mathrm{~Sv}$ at $125 \mathrm{~km}$. Taking this as the upper limit of the plume yields a $w_{e}$ of $5 \times 10^{-4} \mathrm{~m} \mathrm{~s}^{-1}$.

[41] Another useful quantity related to the bulk overflow is the average temperature, which can be approximately determined from the $T$ value at $\frac{1}{2} Q_{4.5}$ in Figure 12 (e.g., the average temperature at $200 \mathrm{~km}$ is just over $2.5^{\circ} \mathrm{C}$; or, using $Q_{4.9}$, the average is just over $3^{\circ} \mathrm{C}$ ). For intermediate layers within the overflow, the divergence/convergence of the $Q$ lines indicates water mass production through diapycnal mixing.

[42] The major overflow characteristics in Figure 12 are as follows: At the sill, although the overflow has already undergone significant mixing, the water is almost entirely colder than $1.5^{\circ} \mathrm{C}$ with a transport of $2.5 \mathrm{~Sv}$. This total transport increases to $3.7 \mathrm{~Sv}(5 \mathrm{~Sv})$ by $200 \mathrm{~km}$ downstream of the sill, as the limiting isotherm has increased to $4.5^{\circ} \mathrm{C}$ $\left(4.9^{\circ} \mathrm{C}\right)$. This large entrainment seems to happen earlier in the model than observed in the in situ data. However, the single largest entrainment event below $4.5^{\circ} \mathrm{C}$ occurs between 60 and $100 \mathrm{~km}$, which is not far from where the observations indicate enhanced mixing. The modeled rate of $4 \times 10^{-4} \mathrm{~m} \mathrm{~s}^{-1}$ over that sharp rise is less than the maximum observed and the enhancement extends over a substantially shorter region. Overall, only the $3-4.9^{\circ} \mathrm{C}$ layer sees any appreciable entrainment, with the majority of this occurring above $4.5^{\circ} \mathrm{C}$.

[43] Note that the mixing and entrainment process reduces the transport of the coldest water while increasing the total overflow. For example, the transport of water colder than $1.5^{\circ} \mathrm{C}$ decreased by more than a factor of 2 and the water colder than $-0.5^{\circ} \mathrm{C}$ has almost entirely disappeared by $150 \mathrm{~km}$. On the other hand, the transport of water colder than $3.5^{\circ} \mathrm{C}$ remains essentially uniform downstream, and the transports in the individual ranges between $-0.5^{\circ} \mathrm{C}$ and $2.5^{\circ} \mathrm{C}$ retain constant values. This indicates that in the colder half of the overflow, a redistribution of water is taking place but only the warmer half is becoming more homogenized.

[44] The total entrainment into the overflow is similar in the model to that observed from dilution rates [Girton and Sanford, 2003] and from current meter transport estimates [Dickson and Brown, 1994], but the model layers affected are substantially lighter. The discrepancy has many possible causes, including mixing parameterizations and topographic resolution, but a likely candidate is simply the absence of a background stratification in the model, which appears to play an important role in setting the location and magnitude of the observed DSO entrainment. In the observed DSO, the decrease in bulk Richardson number $\left(R_{b}\right)$ due to the plume entering denser backgroundwater seems to play a large role in the entrainment process. In addition, the large observed bottom stresses and merged shear layer structure suggest a role for bottom-generated turbulence to influence mixing and interlayer entrainment in the overflow. This process is entirely absent from the model.

\subsection{Plume Hydraulics}

[45] As a descending gravity current with finite supply rate, the DSO is a likely candidate for a hydraulically

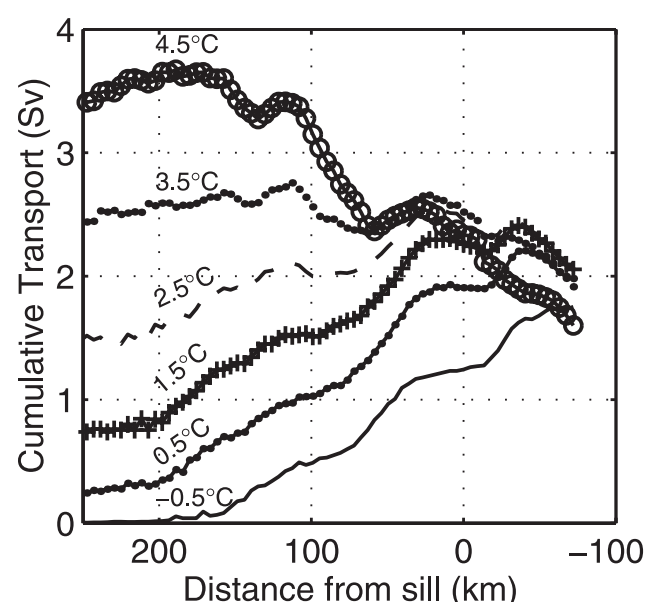

Figure 12. Transport averaged over days 17-32 of the model run for different temperature classes, illustrating the effects of internal mixing and entrainment of warmer (lighter) water as the flow descends. Each line represents the time mean transport of all water colder than a particular temperature, as a function of distance from the sill. Note that the direction of flow is to the left (i.e., southwestward) and that model density is uniquely determined by temperature, so that $2.5^{\circ} \mathrm{C}$ is exactly equivalent to $\sigma_{\theta}=$ $27.8 \mathrm{~kg} \mathrm{~m}^{-3}$. Although not shown in the figure, the transport of water colder than $4.9^{\circ} \mathrm{C}$ (essentially all water influenced by mixing with the cold overflow) increases from about $2.5 \mathrm{~Sv}$ at the sill to $5 \mathrm{~Sv}$ at $125 \mathrm{~km}$. 
controlled flow. While hydraulic arguments have implications for the upstream basin circulation as well as for the relationship between isopycnal heights and volume fluxes, we concentrate here on the evidence for and implications of hydraulic control in the descending flow. One definition of hydraulic control is criticality of the flow with respect to the waves capable of passing information upstream. While both rotation and channel shape can affect the propagation speed of disturbances in a reduced gravity flow, we have chosen to use $c_{w}=\sqrt{g^{\prime} D}$, the speed of both nonrotating long waves and Kelvin waves at vertical boundaries (also the integrated density anomaly presented in Figure 3) as the most likely velocity scale to apply in the DSO. Once the flow reaches a speed $(U)$ greater than $c_{w}$ (i.e., Froude number $F=\frac{U}{\sqrt{g^{\prime} D}}$ equal to or greater than unity), these waves are no longer able to travel upstream and the flow becomes insensitive to downstream conditions.

[46] Figure 13a (thick line) shows the 3-day mean Froude number $(F)$ versus downstream distance. $F$ increases to a maximum about $100 \mathrm{~km}$ from the sill and decreases sharply beyond $200 \mathrm{~km}$. Also shown is the $\pm 2 \sigma$ envelope of $F$ for all of the snapshots for the 3 days used for the mean (days 2931). Thin lines illustrate two snapshots (day 31.67 and 31.83 ), and show two peaks in $F$, corresponding to eddies propagating in the downstream direction. The apparent propagation speeds derived from the two snapshots separated by 4 hours are somewhat different for each variable plotted, but do appear to follow the same general pattern as the velocity curve in Figure 13b, with a maximum around $125 \mathrm{~km}$. The motion of the first $F$ peak (at $\sim 120 \mathrm{~km}$ ) corresponds to $0.4 \mathrm{~m} \mathrm{~s}^{-1}$, while the second (at $200 \mathrm{~km}$ ) is slower at $0.2 \mathrm{~m} \mathrm{~s}^{-1}$. The corresponding peaks in velocity, however, move at $0.6 \mathrm{~m} \mathrm{~s}^{-1}$ and $0.4 \mathrm{~m} \mathrm{~s}^{-1}$, respectively. The wave speed snapshots (Figure 13c) show peaks at markedly different positions from those in the other two variables, with propagation speeds of $0.3 \mathrm{~m} \mathrm{~s}^{-1}$ and $0.4 \mathrm{~m} \mathrm{~s}^{-1}$ at 90 and $170 \mathrm{~km}$.

[47] It is important to recall that the observations (solid dots in Figure 13) cover two cruises with the majority being obtained over a 2-week XCP/XCTD survey on Poseidon 1998. They show $F$ increasing downstream over the region from 0 to $70 \mathrm{~km}$ due to a combination of velocity increase and $c_{w}$ decrease more rapid than in the model. Figure 13b shows that the model velocity reaches a maximum at $125 \mathrm{~km}$. The observations agree with the model results better in the downstream region $(>100 \mathrm{~km})$, but closer to the sill the observations are either too small or too large compared to the model. This may result from the small number of observations or the lesser variability in the model. Figure $13 \mathrm{c}$ exhibits some discrepancy between propagation speeds in the observations compared to the model. Part of this could be a result of the simplified density structure in the model (with somewhat enhanced density contrast) and part could be a result of slightly anomalous sampling period on the Poseidon 1998 cruise. The more representative full 3-year Poseidon/Aranda data set (pluses) shows less of a departure from the model. In any case, the proper wave speed to use for hydraulic considerations is not entirely clear, and may be different for 1.5-layer or two-layer dynamics.

[48] The positioning of the $F>1$ region beyond $100 \mathrm{~km}$ from the sill is an interesting feature which may be related to hydraulic predictions of downstream displacement of the
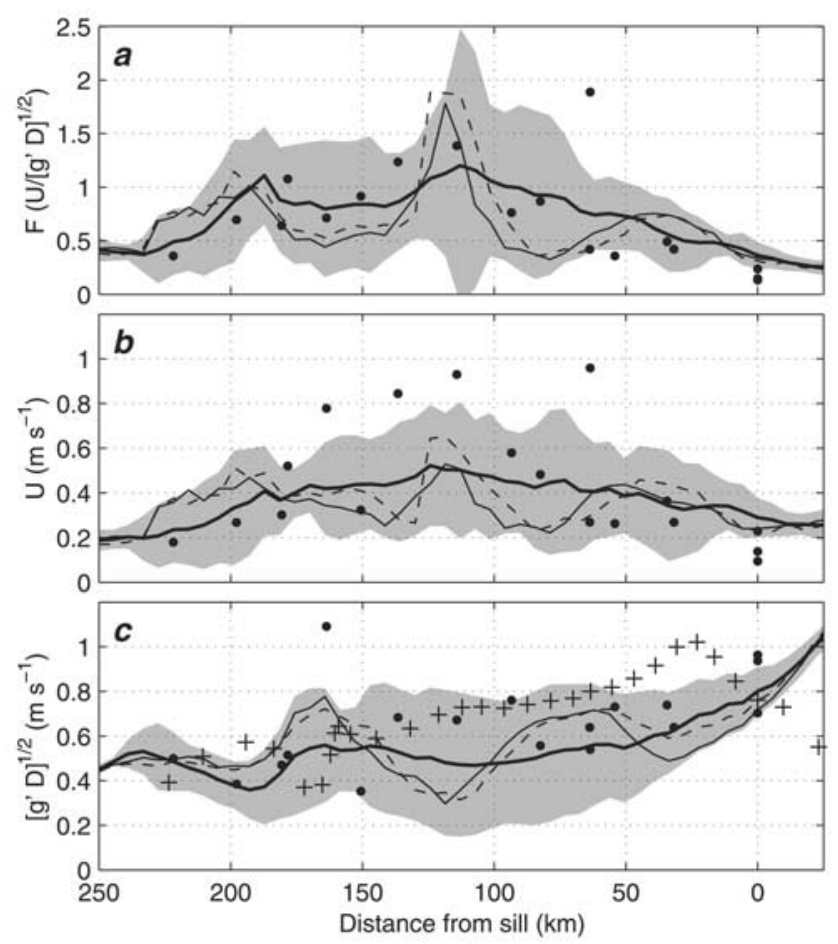

Figure 13. Dense layer Froude number, velocity, and wave speed at the location of maximum overflow velocity in each model cross section. Thick lines are 3-day model means, with $2 \times$ RMS model variability indicated by gray shading. Thin lines indicate model snapshots spaced 4 hours apart at day 31.67 (dashed) and 31.83 (solid). Solid dots indicate observations of (a) the minimum $F$ in each XCP/ XCTD section along with (b) the corresponding flow speed and (c) wave speed. Crosses indicate additional hydrographic measurements from the combined Poseidon/Aranda data set (along the center of gravity path shown in Figure 2), giving an independent estimate of wave speed versus distance.

control section by bottom friction and entrainment [Pratt, 1986; Gerdes et al., 2002]. The shape of the $F$ curve is dominated by $U$, which is strongly influenced by the increase in topographic slope (across the overflow) up to $\sim 125$ from the sill. While it does not appear to be the case from Figure 14 that the control section $(F=1)$ coincides with critical slope $\left(d Z / d \xi=-C_{D}\right)$ [Pratt, 1986], the intense entrainment up to $125 \mathrm{~km}$ could play a role in driving the model overflow toward criticality [Gerdes et al., 2002]. Since the largest entrainment diagnosed from the Poseidon 1998 observations lies after $125 \mathrm{~km}$, this seems less likely to be occurring the real DSO.

[49] It is worth noting that several theoretical predictions argue against hydraulic control as we seem to see it in the DSO. Most theories of rotating flow in flat bottom channels indicate an important relationship between the boundary currents at the two sidewalls, but the analogy to the lefthand (looking along the flow) wall in a realistic topography is not entirely clear. Is a steep wall necessary or is simply any reversal in slope, such as would be found at the talweg (channel axis), sufficient? Pratt et al. [2000] claim that rotating flow in a wide channel (relative to the Rossby 


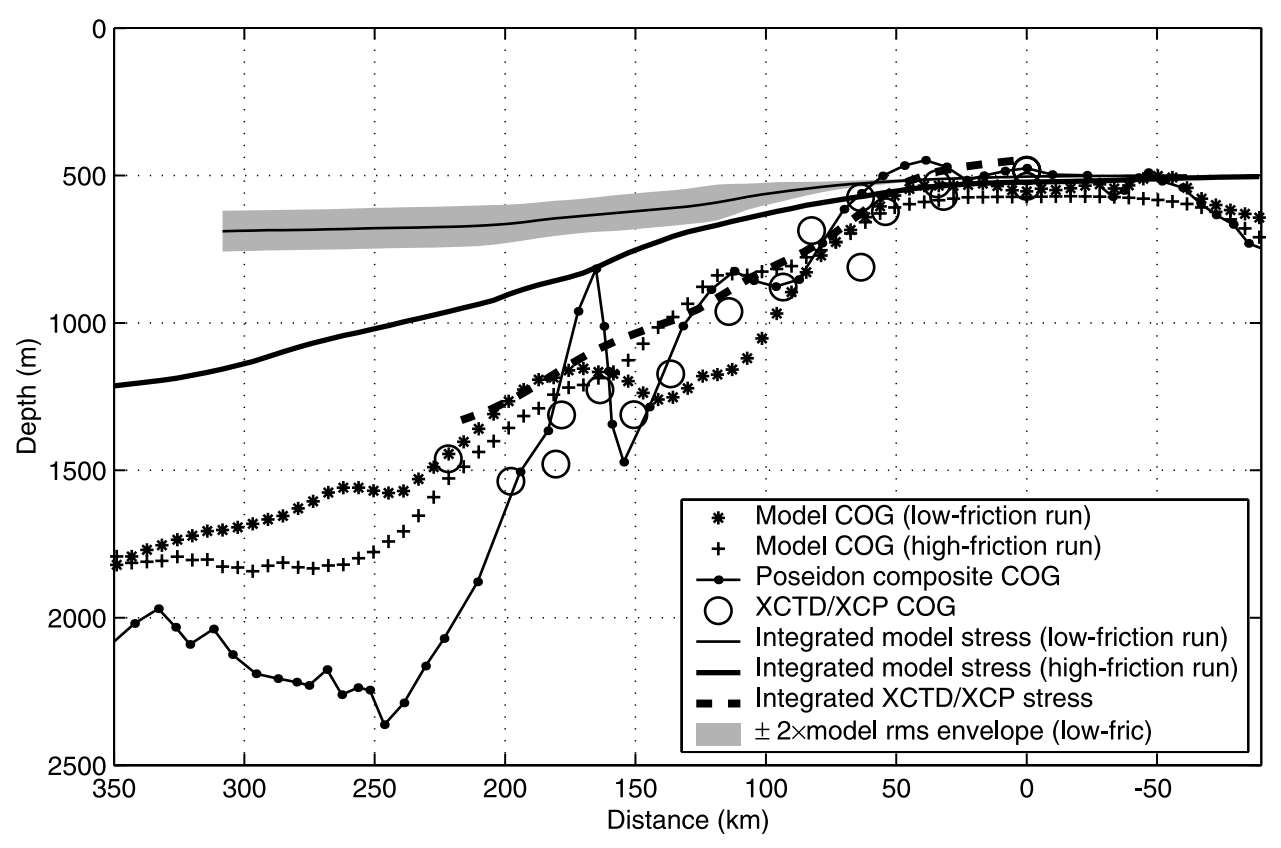

Figure 14. Descent of the overflow with distance from the sill. COG curves track the transportweighted center of gravity of the overflow density anomaly (except for the Poseidon curve, which is not transport weighted, but this appears to have little effect). Integrated stress curves show the expected rate of descent of a reduced gravity stream tube model due to bottom friction $\left(\tau_{b}\right)$ alone (equation $(7)$ ).

deformation radius; in our case, $\sim 5 \mathrm{~km}$ ) is always subcritical when attached to the left-hand wall and supercritical when separated. If the DSO is, in fact, an attached flow (given the extending of the dense water to the talweg in Figures 2 and 3, at least as far as the $2000 \mathrm{~m}$ isobath) then the appearance of critical $F$ in Figure 13 may simply be a result of measuring the wrong quantity. In fact, Pratt [1986] mentions the possibility for noncontrolled flow with an asymmetric "overflow-like" character simply due to the extraction of potential energy by friction. If the flow is actually separated, then a possibility exists for lateral hydraulic jumps (which may in fact be present in the form of moving eddies). It continues to be our feeling that the DSO must be hydraulically controlled in the sense of preventing upstream propagation of information, and that Figure 13a points to a likely location for that control. However, the nature of the information-carrying waves and the reason for the location of the control section remain unclear.

\subsection{Descent and Bottom Stress}

[50] An important function of 1.5-layer gravity current flows is in transporting dense water to depth, so it is worth comparing the rates at which this occurs in both the observed and modeled DSO. A stream tube model would predict that the plume momentum balance is basically among accelerations caused by buoyancy anomaly, Coriolis effect, and friction, including contributions from both bottom stress $\left(\tau_{b}\right)$ and the entrainment of nonmoving fluid $\left(\tau_{e}=\right.$ $\left.\rho w_{e} U\right)$. In this case, the rate change of plume depth $(Z)$ in the downstream direction $(\xi)$ becomes:

$$
\frac{d Z}{d \xi}=\frac{\tau_{b}+\tau_{e}}{\rho g^{\prime} D}
$$

Girton and Sanford [2003] used measured values of $\tau_{b}, \tau_{e}$, $d Z / d \xi$ and $g^{\prime} D$ to argue that this balance holds quite well in the DSO, with about $80 \%$ of the total stress contributed by the bottom. With the use of a quadratic drag law as in the numerical model, $\tau_{b}=\rho C_{D} U^{2}$, the relation can be simplified to

$$
\frac{d Z}{d \xi}=\frac{C_{D} U^{2}+w_{e} U}{g^{\prime} D}=F^{2}\left(C_{D}+\frac{w_{e}}{U}\right),
$$

predicting a relationship to the hydraulics discussed earlier through the Froude number $F$ (provided the 1.5-layer character of the flow is maintained). Unsteadiness and twolayer (or more) effects will tend to invalidate these relationships. For example, a type of potential energy release attributed to finite amplitude baroclinic instability takes the form of intermittent propagating dipoles for which a relationship with bottom and entrainment stress is not necessary [Spall and Chapman, 1998].

[51] We investigate the mechanism of dense water descent in the DSO by comparing the a) observed depth of the overflow center of gravity (COG), b) modeled COG depth, c) observed bottom stress $\left(\tau_{b}\right.$, presented as a cumulative integral of $d Z / d \xi)$ and d) modeled bottom stress (Figure 14). The effects of entrainment stress $\left(\tau_{e}\right)$ will also be discussed, although not included in Figure 14 because of the apparent dominance of the bottom contribution in the observations, together with some ambiguity in the calculation of entrainment stress from the model output. For the case of constant $C_{D} F^{2}$ [e.g., Killworth, 2001], the curve would be a straight line. The observed COG depth (open circles and connected dots) is well reproduced in the model (' + ' and '*' symbols), while the depth expected from the integrated bottom stress is quite different between the model (solid lines) and 
observations (dashed line). In addition, a separate model run (referred to in Figure 14 as "high friction") using $C_{D}=3 \times$ $10^{-3}$ shows very little change in COG descent while the predicted descent rate (from $\int C_{D} F^{2}$ ) approximately doubles. Note that the change in $C_{D}$ produces not only a shift in geostrophic balance toward down-slope flow but also slower near-bottom velocities, with the two effects somewhat canceling in terms of dense water descent.

[52] The failure of $\int C_{D} \mathrm{~F}^{2}$ to predict the model's rate of COG descent is partly explained by the neglect of entrainment stress $\tau_{e}$, though the large production of slightly mixed water (not always included in plume integrals) in the model makes this a bit tricky to evaluate definitively. Using equation (5), the $Q_{4.5}$ slope from Figure 12 and $U$ from Figure 13 gives an essentially steady $w_{e} / U$ value of $4 \times$ $10^{-4}$, less than half of the $C_{D}$ used in the principal (lowfriction) model run. However, a slightly warmer $4.9^{\circ} \mathrm{C}$ definition of the overflow gives $w_{e} / U=1.3 \times 10^{-3}$, suggesting an entrainment stress larger than bottom stress. To make the integrated stress (thin solid line in Figure 14) match the COG would require a $\tau_{e}$ of 3 times $\tau_{b}$, which clearly does not exist. The remaining COG descent likely points to the greater importance of eddy and instability dynamics than the steady state balance with bottom friction. However, the agreement between the observed $\tau_{b}$ and $d Z / d \xi$ suggests that a steady state balance may, in fact, be dominant in the real overflow. Including entrainment in the observed stress integral (thick dashed line in Figure 14) produces only about a $20 \%$ deepening, but it does bring the end point closer in line with the observed COG depth.

\section{Conclusions}

[53] The essential characteristics of the Denmark Strait Overflow have been investigated in a high-resolution numerical process model and compared, where applicable, to the results of a 3-year program of in situ measurements. Through the interaction of a purely density-driven flow with a realistic topography, the model is able to replicate most of the salient features of the observed DSO, including: (1) typical cross-section distributions of dense water in the overflowing plume, (2) the transition from a mostly barotropic velocity structure at the sill to a downstream baroclinic flow, (3) typical length and timescales of variability in the form of transport variations and domes of overflow water, (4) the rate of descent of the dense layer across the topography of the Greenland continental slope, (5) evidence for hydraulic control in the form of a region of supercritical flow downstream of the sill, (6) a mean volume transport of $2.6 \mathrm{~Sv}$ of dense water, and (7) a region of enhanced entrainment coincident with the supercritical flow at $\sim 100 \mathrm{~km}$ from the sill. It is also interesting that the modeled and observed flux of dense water through the Denmark Strait are in close agreement while the maximal value predicted by rotating hydraulic theory [Whitehead, 1989; Killworth and MacDonald, 1993] overestimates the transport by $30-50 \%$. This could potentially be due to many things, including unsteady flow, friction or upstream recirculations. In fact, a minor (but essential) modification to the hydraulic theory to include the realistic topography of the sill section [Borenäs and Nikolopoulos, 2000] is able to reduce the overprediction to a mere $10 \%$, implying that the remaining confounding effects are minimal. Of course, the question still remains which topographic section to use, if the location of control is not directly at the sill.

[54] In addition, the model is able to "fill in" details of the overflow dynamics which are not easily diagnosed from our (still) sparse observations. In this way the connection between dense water domes and cyclonic surface eddies becomes clearer, as does the role of the eddies in the transition from barotropic to baroclinic flows as the overflow descends. While the eddy generation process is difficult to capture in observations, the sequence of events is more easily identified in the model as the result of a pulse of overflow transport which propagates down-slope as a dipole and intensifies through vortex stretching into a pure (barotropic) cyclone.

[55] Of course, not all of the observed DSO characteristics are perfectly represented in the model, which points toward the importance of both unincluded hydrographic characteristics and (possibly) inadequate physics. In particular, the amount of backgroundwater entrained is reasonable but occurs too early and lighter fluid does not get mixed into the deeper parts of the overflow. Several "entrainment laws" have been proposed by various researchers [Christodoulou, 1986; Turner, 1986; Price, 2002]. Though a plot of the $Q_{4.5}$-derived entrainment values (Figure 12 and equation (5)) versus $F$ (Figure 13; or, equivalently, $R_{b}=1 / F^{2}$ ) don't form a particularly tight relationship, they lie closest to the "intermediate" expression proposed by Christodoulou [1986, equation (17)]: $w_{e} / U=0.002 R_{b}^{-1}$. This power law is purported to represent entrainment by a mixture of "vortex" (Kelvin-Helmholtz) and "cusp-like" (Holmboe) shear instabilities (neither of which are resolved by our model). The high-entrainment region in the Poseidon 1998 observations also lies quite close to this line $\left(w_{e} / U \approx 1.6 \times 10^{-3}\right.$, $R_{b} \approx 1.4$ ).

[56] A puzzling difference between the model and observations is the much greater bottom stress computed from measured in situ velocity profiles than arising from the quadratic drag law used in the model. The effect of these stresses on the overflow dynamics is not entirely clear, although one possible result (the expectation that dense water descent will scale with bottom stress) does not appear to carry over into the model. For the model runs considered here, the ultimate rate of descent of dense water was $50-$ $250 \%$ greater than expected because of friction (bottom and entrainment stress) alone.

[57] The ultimate goal of overflow process studies such as ours in the Denmark Strait is often seen to be the improvement of parameterizations to incorporate the effects of small-scale topography or smaller-scale mixing processes into large-scale numerical models. While our study is able to accurately reproduce many aspects of the dynamics of overflows, the model was not designed to produce realistic product waters nor to diagnose the influence of multiple components of source waters. In order to investigate these aspects, a more realistic hydrographic structure would be essential. Nevertheless, a number of elements of our study, including the localization of regions of hydraulic control and mixing, the relationship between transport and upstream density structure and the rates of dense water descent and spreading should be of use in the development of overflow and bottom boundary layer parameterizations. 
[58] Acknowledgments. We are grateful for the vital contributions by John Dunlap of APL/UW and Janko Hauser of IfM Kiel to the field operations and data processing. Bert Rudels and Riikka Hietala of FIMR kindly provided CTD and ADCP data from the Aranda cruise. This research was supported by grants NSF OCE-9712313 and OCE-0099275 (USA) and SFB-460:A1 (Germany) and by the Postdoctoral Scholar Program at the Woods Hole Oceanographic Institution, with funding provided by the NOAA/UCAR Climate and Global Change program and the J. Seward Johnson Fund. WHOI contribution number 10817.

\section{References}

Aagaard, K., and S.-A. Malmberg, Low-frequency characteristics of the Denmark Strait Overflow, in ICES CM 1978/C:47, Int. Counc. for the Explor. of the Sea, Copenhagen, 1978.

Bacon, S., Decadal variability in the outflow from the Nordic Seas to the deep Atlantic Ocean, Nature, 394, 871-874, 1998

Beckmann, A., and R. Döscher, A method for improved representation of dense water spreading over topography in geopotential-coordinate models, J. Phys. Oceanogr., 27, 581-591, 1997.

Borenäs, K., and A. Nikolopoulos, Theoretical calculations based on real topography of the maximal deep-water flow through the Jungfern passage, J. Mar. Res., 58, 709-719, 2000

Bruce, J. G., Eddies southwest of the Denmark Strait, Deep Sea Res., Part I, 42, 13-29, 1995.

Christodoulou, G. C., Interfacial mixing in stratified flows, J. Hydraul. Res., 24, 77-92, 1986.

Dickson, B., J. Meincke, I. Vassie, J. Jungclaus, and S. Østerhus, Possible predictability in overflow from the Denmark Strait, Nature, 397, $243-$ 246, 1999.

Dickson, B., I. Yashayaev, J. Meincke, B. Turrell, S. Dye, and J. Holfort, Rapid freshening of the deep North Atlantic Ocean over the past four decades, Nature, 416, 832-837, 2002.

Dickson, R. R., and J. Brown, The production of North Atlantic Deep Water: Sources, rates, and pathways, J. Geophys. Res., 99, 12,319$12,341,1994$.

Fristedt, T., R. Hietala, and P. Lundberg, Stability properties of a barotropic surface-water jet observed in the Denmark Strait, Tellus, Ser. A, 51, 979989, 1999.

Gerdes, F., C. Garrett, and D. Farmer, On internal hydraulics with entrainment, J. Phys. Oceanogr., 32, 1106-1111, 2002.

Gill, A. E., The hydraulics of rotating-channel flow, J. Fluid Mech., 80, $641-671,1977$.

Girton, J. B., Dynamics of transport and variability in the Denmark Strait Overflow, Ph.D. thesis, Univ. of Wash., Seattle, 2001.

Girton, J. B., and T. B. Sanford, Descent and modification of the overflow plume in the Denmark Strait, J. Phys. Oceanogr., in press, 2003.

Girton, J. B., T. B. Sanford, and R. H. Käse, Synoptic sections of the Denmark Strait overflow, Geophys. Res. Lett., 28, 1619-1622, 2001.

Holland, D. M., R. Rosales, D. Stefanica, and E. G. Tabak, Internal hydraulic jumps and mixing in two-layer flows, J. Fluid Mech., 470, 6383, 2002.

Jiang, L., and R. W. Garwood Jr., Three-dimensional simulations of overflows on continental slopes, J. Phys. Oceanogr., 26, 1214-1233, 1996.

Johnson, G. C., and T. B. Sanford, Secondary circulation in the Faroe Bank Channel outflow, J. Phys. Oceanogr., 22, 927-933, 1992.

Jungclaus, J. H., and J. O. Backhaus, Application of a transient reduced gravity plume model to the Denmark Strait Overflow, J. Geophys. Res., 99, 12,375-12,396, 1994.

Jungclaus, J. H., J. Hauser, and R. H. Käse, Cyclogenesis in the Denmark Strait overflow plume, J. Phys. Oceanogr., 31, 3214-3229, 2001.

Käse, R. H., and A. Oschlies, Flow through Denmark Strait, J. Geophys. Res., 105, 28,527-28,546, 2000.

Käse, R. H., A. Biastoch, and D. B. Stammer, On the mid-depth circulation in the Labrador and Irminger seas, Geophys. Res. Lett., 28, 3433-3436, 2001.

Killworth, P. D., Mixing on the Weddell Sea continental slope, Deep Sea Res., 24, 427-448, 1977

Killworth, P. D., On the rate of descent of overflows, J. Geophys. Res., 106, 22,267-22,275, 2001.

Killworth, P. D., and N. R. Edwards, A turbulent bottom boundary layer code for use in numerical ocean models, J. Phys. Oceanogr., 29, $1221-$ 1238,1999

Killworth, P. D., and N. R. MacDonald, Maximal reduced-gravity flux in rotating hydraulics, Geophys. Astrophys. Fluid Dyn., 70, 31-40, 1993.

Krauss, W., and R. H. Käse, Eddy formation in the Denmark Strait overflow, J. Geophys. Res., 103, 15,525-15,538, 1998.

Lane-Serff, G. F., and P. G. Baines, Eddy formation by dense flows on slopes in a rotating fluid, J. Fluid Mech., 363, 229-252, 1998.

Lavender, K. L., R. E. Davis, and W. B. Owens, Mid-depth recirculation observed in the interior Labrador and Irminger Seas by direct velocity measurements, Nature, 407, 66-69, 2000.
Marotzke, J., and J. Willebrand, The North Atlantic mean circulation: Combining data and dynamics, in The Warmwatersphere of the North Atlantic, edited by W. Krauss, chap. 20, pp. 55-90, Borntraeger, Berlin, 1996.

Mauritzen, C., and S. Hakkinen, On the relationship between dense water formation and the "meridional overturning cell" in the North Atlantic ocean, Deep Sea Res., Part I, 46, 877-894, 1999.

McCartney, M., K. Donohue, R. Curry, C. Mauritzen, and S. Bacon, Did the overflow from the Nordic Seas intensify in 1996-1997?, Int. WOCE Newsl., 31, 3-7, 1998.

Munk, W., L. Armi, K. Fisher, and F. Zachariasen, Spirals on the sea, Proc. R. Soc. London, Ser. A, 456, 1217-1280, 2000.

Pratt, L. J., Hydraulic control of sill flow with bottom friction, J. Phys. Oceanogr., 16, 1970-1980, 1986

Pratt, L. J., and P. A. Lundberg, Hydraulics of rotating strait and sill flow, Annu. Rev. Fluid Mech., 23, 81-106, 1991

Pratt, L. J., K. R. Helfrich, and E. P. Chassignet, Hydraulic adjustment to an obstacle in a rotating channel, J. Fluid Mech., 404, 117-149, 2000.

Price, J., Overflows and the large-scale circulation: A review, paper presented at Second Meeting on the Physical Oceanography of Sea Straits, Off. of Nav. Res., Villefranche, France, 2002.

Price, J. F., and M. O. Baringer, Outflows and deep water production by marginal seas, Progr. Oceanogr., 33, 161-200, 1994.

Ross, C. K., Overflow variability in Denmark Strait, in ICES CM 1978/ $C: 21$, Int. Counc. for the Explor. of the Sea, Copenhagen, 1978.

Ross, C. K., Temperature-salinity characteristics of the "overflow" water in Denmark Strait during “OVERFLOW'73”, Rapp. P. V. Reun. Cons. Int. Explor. Mer., 185, 111-119, 1984.

Rudels, B., P. Eriksson, H. Grönvall, R. Hietala, and J. Launiainen, Hydrographic observations in Denmark Strait in fall 1997, and their implications for the entrainment into the overflow plume, Geophys. Res. Lett., 26, 1325-1328, 1999.

Rydberg, L., Rotating hydraulics on deep-water channel flow, Tellus, 32, $77-89,1980$

Sanford, T. B., R. G. Drever, J. H. Dunlap, and E. A. D’Asaro, Design, operation and performance of an expendable temperature and velocity profiler (XTVP), Tech. Rep. APL/UW 8110, Appl. Phys. Lab., Univ. of Wash., Seattle, 1982.

Shi, X. B., L. P. Røed, and B. Hackett, Variability of the Denmark Strait overflow: A numerical study, J. Geophys. Res., 106, 22,277-22,294, 2001.

Smith, P. C., A streamtube model for bottom boundary currents in the ocean, Deep Sea Res., 22, 853-873, 1975.

Smith, P. C., Baroclinic instability in the Denmark Strait Overflow, J. Phys. Oceanogr., 6, 355-371, 1976.

Smith, W. H. F., and D. T. Sandwell, Global sea floor topography from satellite altimetry and ship depth soundings, Science, 277, 1956-1962, 1997.

Spall, M. A., and D. C. Chapman, On the efficiency of baroclinic eddy heat transport across narrow fronts, J. Phys. Oceanogr., 28, 2275-2287, 1998.

Spall, M. A., and J. F. Price, Mesoscale variability in Denmark Strait: The PV outflow hypotheses, J. Phys. Oceanogr., 28, 1598-1623, 1998.

Swaters, G. E., On the baroclinic instability of cold-core coupled density fronts on a sloping continental shelf, J. Fluid Mech., 224, 361-382, 1991.

Turner, J. S., Turbulent entrainment: The development of the entrainment assumption, and its application to geophysical flows, J. Fluid Mech., 173, 431-471, 1986 .

Whitehead, J. A., Internal hydraulic control in rotating fluids-Applications to oceans, Geophys. Astrophys. Fluid Dyn., 48, 169-192, 1989.

Whitehead, J. A., A. Leetmaa, and R. A. Knox, Rotating hydraulics of strait and sill flows, Geophys. Fluid Dyn., 6, 101-125, 1974.

Whitehead, J. A., M. E. Stern, G. R. Flierl, and B. A. Klinger, Experimental observations of baroclinic eddies on a sloping bottom, J. Geophys. Res., 95, 9585-9610, 1990.

Willebrand, J., B. Barnier, C. Böning, C. Dieterich, P. D. Killworth, C. LeProvost, Y. Jia, J.-M. Molines, and A. L. New, Circulation characteristics in three eddy-permitting models of the North Atlantic, Prog. Oceanogr., 48, 123-161, 2001.

Worthington, L. V., An attempt to measure the volume transport of Norwegian Sea overflow water through the Denmark Strait, Deep Sea Res., 16, $421-432,1969$.

J. B. Girton, MS 29, Woods Hole Oceanographic Institution, Woods Hole, MA 02543, USA. (girton@whoi.edu)

R. H. Käse, Institut für Meereskunde an der Universität Kiel, 24105 Kiel, Germany.

T. B. Sanford, Applied Physics Laboratory and School of Oceanography, University of Washington, Seattle, WA 98105, USA. 